\title{
Diurnal Cycle of Surface Winds in the Maritime Continent Observed through Satellite Scatterometry
}

\author{
Ewan Short, Claire L. Vincent, And Todd P. LANE \\ School of Earth Sciences, and ARC Centre of Excellence for Climate Extremes, University \\ of Melbourne, Melbourne, Victoria, Australia
}

(Manuscript received 8 December 2018, in final form 4 March 2019)

\begin{abstract}
The diurnal cycle of surface winds throughout the Maritime Continent plays a significant role in the formation of precipitation over the islands of the region and over the surrounding seas. This study investigates the connection between the diurnal cycles of surface wind and offshore precipitation using data from four satellite scatterometer instruments and two satellite precipitation radar instruments. For the first time, data from three scatterometer instruments are combined to yield a more temporally complete picture of the surface wind diurnal cycles over the Maritime Continent's surrounding seas. The results indicate that land-sea breezes typically propagate over $400 \mathrm{~km}$ offshore, produce mean wind perturbations of between 1 and $5 \mathrm{~m} \mathrm{~s}^{-1}$, and propagate as gravity waves at $25-30 \mathrm{~m} \mathrm{~s}^{-1}$. Diurnal precipitation cycles are affected through gravity wave propagation processes associated with the land-sea breezes, and through the convergence of land breezes from nearby islands. These observational results are then compared with previous mesoscale modeling results. It is shown that land-sea breezes occur too early, and are too intense in these modeling results, and this may partly explain why these modeling results also exhibit an early, overly intense diurnal precipitation cycle. This study also investigates variations in the diurnal cycle of surface winds at seasonal and intraseasonal time scales. Previous work has suggested that seasonal and intraseasonal variations in surface heating affect the land-sea breeze circulation and diurnal precipitation cycles; we argue that variations in background winds also play a defining role in modulating coastally influenced local winds.
\end{abstract}

\section{Introduction}

The Maritime Continent (Fig. 1) is one of the rainiest places on the planet. Deep convection over the islands of the region transports large amounts of moisture to the upper troposphere (Ramage 1968), helping to maintain the Hadley and Walker circulations, which in turn affect precipitation across the globe. Diurnal precipitation cycles account for $\approx 50 \%$ of the mean precipitation of each island and the nearby seas, extending to above $80 \%$ over some mountainous areas (Love et al. 2011). Furthermore, around $40 \%-60 \%$ of the Maritime Continent's precipitation has been attributed to coastal processes such as the land-sea breeze (Bergemann et al. 2015). Furthermore, some global models have been shown to underestimate precipitation over the Maritime Continent (Neale and Slingo 2003), and because diurnal precipitation cycles contribute significantly to

\footnotetext{
Corresponding author: Ewan Short, shorte1@student.unimelb. edu.au
}

the region's total precipitation, an improved understanding of these cycles may provide guidance as to how the simulation of precipitation could be improved.

Mori et al. (2004) considered the diurnal precipitation cycle around Sumatra and its surrounding oceans using three years of Tropical Rainfall Measuring Mission data covering 1998-2000. They found that convective rainfall over Sumatra peaked over the island's main mountain range between 1500 and 2000 LST. It then propagated up to $400 \mathrm{~km}$ inland and offshore. Southwest of Sumatra the propagation speed for the first $\approx 100 \mathrm{~km}$ was $\approx 11 \mathrm{~m} \mathrm{~s}^{-1}$, increasing to at least $30 \mathrm{~m} \mathrm{~s}^{-1}$ over the next $300 \mathrm{~km}$. Rainfall peaked just offshore between 0400 and 0700 LST. Propagation behavior was explained in terms of the land-sea breeze.

Hassim et al. (2016) and Vincent and Lane (2016a) examined the diurnal cycle of precipitation around New Guinea using the Weather Research and Forecasting (WRF) Model and satellite precipitation radar data. They found that precipitation associated with convective clouds propagated offshore at two distinct speeds. 


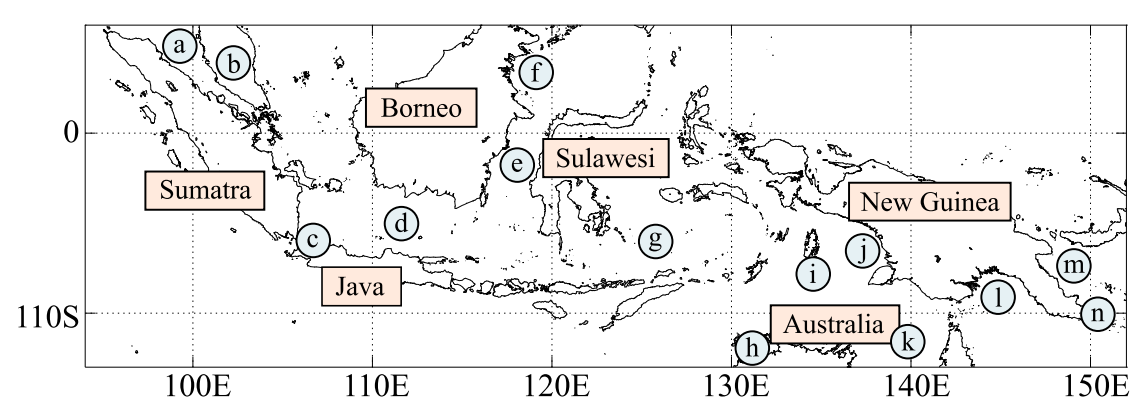

FIG. 1. Map of the Maritime Continent (over the domain considered in Vincent and Lane 2017) and the key regions referred to in this paper: (a) the Strait of Malacca, (b) the Malaysian Peninsula, (c) Jakarta, (d) the Java Sea, (e) the Makassar Strait, (f) the Celebes Sea, (g) the Banda Sea, (h) Darwin, (i) the Aru Islands, (j) Flamingo Bay, (k) the Gulf of Carpentaria, (l) the Gulf of Papua, (m) the Huon Gulf, and (n) the Papuan Peninsula.

Within $100-200 \mathrm{~km}$ of the coast, precipitation propagated at $\approx 5 \mathrm{~m} \mathrm{~s}^{-1}$ with density currents associated with the land and mountain breezes. Between 200 and $700 \mathrm{~km}$ from the coast, precipitation propagated at $12-18 \mathrm{~m} \mathrm{~s}^{-1}$. These faster propagation speeds were attributed to the destabilizing influence of cool anomalies associated with the land breeze, which in the tropics, propagates offshore as a gravity wave (Rotunno 1983; Mapes et al. 2003).

Kilpatrick et al. (2017) studied the Bay of Bengal using scatterometer data from the QuikSCAT Tandem Mission which ran from April to October 2003, along with satellite precipitation and reanalysis data. Kilpatrick et al. found that the diurnal cycle of precipitation in the western Bay of Bengal was associated with the diurnal cycle of surface wind convergence, where offshore and onshore wind perturbations met. They noted that the propagation of surface convergence is closely timed with the propagation of the cooling anomalies described in the studies above, and suggested that the two mechanisms work together to trigger convection.

The above studies examined just a single season, or composites of all seasons, and only Vincent and Lane (2016a) considered intraseasonal variability, the dominant component of which is the Madden-Julian oscillation (MJO) (Madden and Julian 1971, 1972). Vincent and Lane (2016a) provided a case study of a single month, and although this work was later expanded into a 10-yr climatology (Vincent and Lane 2017), this climatology included the austral summer season only. A deeper examination of how diurnal processes vary both seasonally and intraseasonally is therefore required. Rauniyar and Walsh (2011) argued that the MJO affects diurnal cycles of surface winds through changes to surface heating, with reduced cloud cover during convectively suppressed phases increasing the amount of solar radiation that reaches the surface, thus strengthening the landsea breezes, with subsequent effects on the diurnal precipitation cycle. However, Peatman et al. (2014) showed that although the diurnal cycle of precipitation was indeed enhanced during MJO suppressed periods, it was only enhanced shortly before the main MJO convective envelope arrived over each island, but not after. This result was corroborated through the modeling work of Birch et al. (2016). Vincent and Lane (2016a) argued that this asymmetry could be explained by the greater moisture availability shortly before the MJO convective envelope arrived, which is then consumed as the MJO passes.

This study has two aims. First, to assess the offshore behavior of the Maritime Continent's diurnal wind cycles using satellite scatterometer observations. So far, detailed studies of the Maritime Continent's diurnal wind cycles have relied on mesoscale models like WRF, as widespread in situ observations are generally lacking over the region's seas. However, the growing record of satellite scatterometer data provides a new observational dataset that can be used for this purpose. This study presents a new method of utilizing these datasets by combining scatterometer data from multiple satellites and instruments. The surface wind diurnal cycles resolved in this way can then be compared with precipitation diurnal cycles from satellite precipitation radar. Because this method is based solely on observational data, it provides a way of assessing the conclusions of the modeling studies discussed above.

The second goal of this study is to investigate how seasonal and intraseasonal variability in the climate and weather of the Maritime Continent affects the diurnal wind cycle. Some previous studies have commented on this issue (e.g., Rauniyar and Walsh 2011; Peatman et al. 2014), but these studies were based either on models or satellite precipitation radar data-the question has not been directly addressed using wind observations. The present study will therefore consider this question by compositing long records of satellite scatterometer data 
into seasonal and intraseasonal weather/climate categories, then comparing the diurnal wind cycles of each.

The remainder of this paper is organized as follows. Section 2 describes the datasets and methods of the study, sections 3 and 4 present results, and sections 5 and 6 provide a discussion and conclusions, respectively.

\section{Data and methods}

This study considers data from four satellite scatterometer instruments, two satellite precipitation radar instruments, and a mesoscale model. The diurnal signal is extracted from these datasets and composited over long time periods. Statistical techniques are then used to identify where significant diurnal signals exist, and where significant differences between the diurnal signals of different weather/climate states can be found.

\section{a. Data}

Data from four satellite scatterometer instruments are considered in this study: the Advanced Scatterometer (ASCAT), OceanSat Scatterometer (OSCAT), the Haiyang-2 Scatterometer (HY2SCAT), and the Rapid Scatterometer (RSCAT) (NASA 2018b; National Satellite Ocean Application Service 2018). ASCAT instruments are present on two satellites, MetOp-A and $M e t O p-B$, whereas OSCAT and HY2SCAT instruments are carried by the OceanSat-2 and Haiyang-2A $(H Y-2 A)$ satellites, respectively. RSCAT is carried on board the International Space Station (ISS). This study uses level 2B (e.g., National Satellite Ocean Application Service 2013 , p. 1) products for each scatterometer, and the coastally optimized version of ASCAT (Verhoef et al. 2012).

The MetOp-A and -B, OceanSat-2, and Haiyang- $2 A$ satellites all have near polar sun-synchronous orbits; each satellite makes at least one "ascending" (northward) and one "descending" (southward) pass over the Maritime Continent at roughly the same local time each day. For example, the MetOp- $A$ and $-B$ satellites make ascending passes between 0845 and 1015 local solar time (LST) and descending passes between 2045 and 2215 LST. RSCAT data are different to that of the other scatterometers as ISS's orbit is not sun-synchronous: this means RSCAT can sample the same location at different times on different days. It takes several days for each of ASCAT, OSCAT, HY2SCAT, and RSCAT to obtain complete spatial coverage of the Maritime Continent. Understanding surface wind patterns over the entire region therefore necessitates compositing data over long time periods.

OSCAT, HY2SCAT, and RSCAT emit microwave radiation at a $\mathrm{Ku}$-band frequency of approximately
$13 \mathrm{GHz}$, whereas ASCAT operates at the lower C-band frequency of $5.255 \mathrm{GHz}$. This makes ASCAT less sensitive to rain, and more accurate than HY2SCAT or OSCAT (Wu and Chen 2015), although all of the scatterometer datasets are developed using algorithms that account for the presence of rain and adjust the wind fields accordingly. Furthermore, OSCAT exhibits zonal wind measurements in some parts of its swath that are biased relative to other parts. OceanSat-2 repeats an identical orbit every two days, so these biases do not get smoothed out by compositing (Moroni et al. 2013, their Fig. 4).

Two satellite precipitation radar datasets are also considered (NASA 2018c). The first comes from the Tropical Rainfall Measuring Mission (TRMM) and the second from the Global Precipitation Mission (GPM). TRMM ran from late November 1997 to 15 April 2015 (NASA 2018d). GPM is the successor mission, with the Core Observatory satellite being launched on 27 February 2014 and remaining currently operational today (NASA 2018a). This study uses the 3G68 and 2ADPR products for TRMM and GPM, respectively.

Both the TRMM and GPM missions employ a number of instruments, but spaceborne precipitation radar form a central part of each. Previous studies of the Maritime Continent using TRMM have found that the timing of the diurnal cycle of precipitation can be resolved most accurately if just the precipitation radar data are used (Rauniyar and Walsh 2011). Because the timing of the diurnal precipitation cycle is a focus of this study, only the TRMM and GPM precipitation radar datasets are considered.

The GPM precipitation radar is slightly more sensitive than that of TRMM: it is capable of detecting light precipitation of $0.5 \mathrm{~mm} \mathrm{~h}^{-1}$ or less, whereas the TRMM radar is not (Hou et al. 2014). As with RSCAT, the orbits of the TRMM and GPM precipitation radar satellites are not sun-synchronous, so temporal bin sizes can be chosen freely. However, Negri et al. (2002) concluded that a 4-h temporal bin size is optimal when using TRMM precipitation radar to resolve the diurnal cycle, and for consistency, the same bin size has also been used for the GPM data.

This study also utilizes Weather Research and Forecasting (WRF) Model, version 3.5, simulation data from a study of the Maritime Continent conducted by Vincent and Lane (2016b, 2017). WRF uses fully compressible, Euler nonhydrostatic equations (Skamarock et al. 2008), and the simulation of Vincent and Lane covers the 10 austral summers between 2005 and 2015 . The simulation uses a horizontal grid spacing of $4 \mathrm{~km}$ and data are available at a 1-h temporal resolution [see Vincent and Lane (2017) for further details]. 
TABLE 1. Summary of scatterometer data availability. Sample times are the times in LST where each satellite samples the Maritime Continent; $P_{1}$ and $P_{2}$ are the periods of a single orbit and a complete cycle of orbits, respectively. ASCAT, OSCAT, and HY2SCAT data overlap between 29 Oct 2012 and 20 Feb 2014. Data sourced from Indian Space Research Organisation (2007), Royal Netherlands Meteorological Institute (2013), Moroni et al. (2013), Moroni et al. (2016), Satellite Ocean Application Service (2013), and Earth Observation Portal (2018a,b).

\begin{tabular}{lccrrr}
\hline \hline Satellite/instrument & Frequency $(\mathrm{GHz})$ & \multicolumn{1}{c}{ Mission duration } & Sample times $(\mathrm{LST})$ & $P_{1}(\mathrm{~min})$ & $P_{2}(\mathrm{days})$ \\
\hline Metop-A/ASCAT & 5.255 & 18 Aug 2010-present & 0845-1015. 2045-2215 & 101.36 \\
Metop-B/ASCAT & 5.255 & 29 Oct 2012-present & 0845-1015. 2045-2215 & 101.36 \\
OceanSat-2/OSCAT & 13.515 & 16 Jan 2010-20 Feb 2014 & 1055-1255, 2255-0055 & 99.31 \\
HY-2A/HY2SCAT & 13.25 & 1 Oct 2011-present & 0500-0700, 1700-1900 & 104.46 \\
ISS/RSCAT & 13.4 & 3 Oct 2014-19 Aug 2016 & - & 29 \\
\hline
\end{tabular}

Finally, this study uses National Oceanic and Atmospheric Administration (NOAA) satellite observed outgoing longwave radiation (OLR) data to calculate the average OLR during different time periods (NOAA 2019).

\section{b. Resolving diurnal cycles}

The ASCAT, OSCAT, and HY2SCAT instruments operated concurrently between 29 October 2012 and 20 February 2014. Together these instruments provide estimates of the surface winds during the six time windows 0500-0700, 0845-1015, 1055-1255, 1700-1900, 2045-2215, and 2255-0055 LST (see Table 1 for details). This sampling suggests the possibility of combining data from the three instruments to better resolve the diurnal cycle.

Wu and Chen $(2015$, p. 1185) conducted a study of ASCAT, OSCAT, and HY2SCAT and calculated biases in both wind speed and direction as a function of wind speed. For speeds between 5 and $15 \mathrm{~m} \mathrm{~s}^{-1}$ the average bias in wind speed between the products was $0.3 \mathrm{~m} \mathrm{~s}^{-1}$. The average bias in wind direction was $3.35^{\circ}$. The average speed bias for winds less than $5 \mathrm{~m} \mathrm{~s}^{-1}$ was greater, at $0.62 \mathrm{~m} \mathrm{~s}^{-1}$, but slightly less for wind direction, at $3.11^{\circ}$. Given the wind speeds throughout the Maritime Continent are generally between 2 and $14 \mathrm{~m} \mathrm{~s}^{-1}$, these biases are small enough that combining the products yields coherent results.

Each dataset provides ungridded samples within two time windows each day, giving a total of six possible time windows where data are available. To form the combined dataset-which hereafter will be referred to as CSCAT for "combined scatterometer data"- the ASCAT, OSCAT, and HY2SCAT data are first binned separately into regular longitudelatitude-time grids. A horizontal resolution of $0.25^{\circ}$ is used in each case. The data from each instrument is then ordered temporally to form the combined dataset-CSCAT. The values in each of the six time bins can then be averaged over a long time period to form composites (i.e., all the 0500-0700 observations averaged, then all the 0845-1015 observations averaged, and so forth).

Because the focus of this study is the diurnal cycle of surface winds, the diurnally varying component of the CSCAT winds needs to be isolated from variations at longer time scales. This is conceptually difficult as scatterometer data are extremely sparse in space and time. ASCAT does not usually sample the same spatial points during its morning and evening passes; furthermore ASCAT, OSCAT, and HY2SCAT sample different regions on different days.

To overcome this limitation of scatterometer data, the approach developed in this study was to define a background wind corresponding to each observation: this background wind was formed by taking a 1-day running mean, with missing values replaced using a temporal nearest-neighbor interpolation. For instance, if today's 0500-0700 and 2045-2215 LST observations are missing at a given spatial grid cell, use tomorrow's, or yesterday's instead. For each observation, a wind perturbation can then be defined by subtracting the appropriate background wind from that observation. Once perturbations have been calculated for the entire CSCAT time period they can be composited as described above to obtain six perturbation composites. These perturbation composites represent the mean diurnal cycle of surface wind perturbations over the CSCAT time period from 29 October 2012 to 20 February 2014.

The CSCAT perturbation composites can then be compared to perturbation composites calculated from RSCAT alone, since the ISS's non-sun-synchronous orbit allows RSCAT to sample the full diurnal cycle. RSCAT operated between 3 October 2014 and 19 August 2016, covering different years and running about 6 months longer than the combined period of CSCAT. When a 4-h temporal bin is used for RSCAT there are again six time windows per day. Perturbation composites are calculated in the same manner as CSCAT, the main difference being that in the case of CSCAT background winds are formed from data no more than 4 days apart, whereas with RSCAT data up to 30 days apart is 
usually required. Note that the CSCAT operational time period overlaps that of TRMM, so to examine how the diurnal cycles of winds and precipitation covary, the CSCAT composites can be paired with precipitation composites calculated from TRMM data; an analogous pairing can also be made between RSCAT and TRMM.

When RSCAT is restricted to the period from 29 October 2014 to 20 February 2016 so that it covers the same part of the annual cycle as CSCAT, the perturbation composites become less coherent and statistical significance is lost: thus the entire RSCAT record is used. This means that RSCAT and CSCAT composites weight the seasonal cycle differently, with the RSCAT time period including two austral summers and two austral winters and the CSCAT time period including two austral summers but only one austral winter. Furthermore, the time periods of RSCAT and CSCAT encompass different phases of El Niño-Southern Oscillation (ENSO): the RSCAT time period encompasses the 2015/16 El Niño event, whereas the CSCAT time period encompasses neutral ENSO conditions (NOAA 2018). Comparing the CSCAT perturbation composites with those of RSCAT, therefore, provides an estimate of the uncertainties that arise due to the different instruments, background winds, time periods, and ENSO states.

Finally, the CSCAT perturbation composites can also be compared with perturbation composites calculated from the WRF dataset of Vincent and Lane (2016b, 2017). The WRF data are first binned into a $0.25^{\circ}$, 4-h grid, so as to match the resolution of CSCAT as closely as possible. Note that WRF winds are $10-\mathrm{m}$ winds, but scatterometer winds are equivalent neutral winds-these are the hypothetical $10-\mathrm{m}$ winds that would result from neutral stability. Brown et al. (2017) found that in the coastal waters around Darwin, Australia, the bias resulting from these two definitions did not exceed $0.5 \mathrm{~m} \mathrm{~s}^{-1}$. Moreover, in this study it is the wind perturbations from each dataset that are being compared, so unless the biases associated with these different definitions vary significantly with time of day, the perturbations will be minimally affected.

\section{c. Seasonal and intraseasonal variability}

The effects of seasonal and intraseasonal weather/ climate variability on the Maritime Continent's diurnal cycles of surface winds are assessed using ASCAT data from 1 November 2012 to 30 April 2017: using a single scatterometer product allows us to analyze a longer time period than the combined product that relies on the coincident availability of multiple instruments.

The seasonal cycle is divided into two categories, herein referred to as the "Australian monsoon," which
TABLE 2. The Wheeler and Hendon (2004) phases chosen by Rauniyar and Walsh (2011) to correspond to active and suppressed MJO phases.

\begin{tabular}{lcc}
\hline \hline Longitude & Active & Suppressed \\
\hline$<110^{\circ} \mathrm{E}$ & $3,4,5$ & $1,2,6,7,8$ \\
$110^{\circ}-120^{\circ} \mathrm{E}$ & 4,5 & $1,2,3,6,7,8$ \\
$120^{\circ}-140^{\circ} \mathrm{E}$ & $4,5,6$ & $1,2,3,7,8$ \\
$>140^{\circ} \mathrm{E}$ & $4,5,6,7$ & $1,2,3,8$ \\
\hline
\end{tabular}

spans the months of November to April, and the "Asian monsoon," which covers May to October: these definitions are based on those of Laing and Evans (2018). The MJO is described using the "Wheeler-Hendon index" (Wheeler and Hendon 2004; Bureau of Meteorology 2018) which, following Rauniyar and Walsh (2011), is simplified into "active" and "suppressed" categories in accordance with Table 2. Days where the amplitude of the Wheeler-Hendon index is less than 1 are ignored. Ideally, the ASCAT data might also be partitioned into additional categories, but finer division is precluded by the size of the datasets, and the need to retain statistically significant differences between perturbation composites.

The two seasonal and two MJO categories therefore partition the ASCAT data into four subsets. Each subset is then composited as described above. Because ASCAT only samples the Maritime Continent between 08451015 and 2045-2215 LST, and perturbations are defined by subtracting an approximate daily mean from each observation, the resulting perturbation composites for 0845-1015 and 2045-2215 LST are, therefore, almost perfectly symmetric. Thus, the magnitude of these perturbations provide a lower bound for the amplitude of the surface wind diurnal cycle, but say little about its timing (Brown et al. 2017).

\section{d. Statistical methods}

The Hotelling $T^{2}$ test (Rencher 1998, p. 85) with the heteroscedastic approximation of $\mathrm{Nel}$ and Merwe (1986) is used to assess where statistically significant differences between pairs of wind perturbation composites exist. This test is used to check for differences between morning and evening ASCAT perturbation composites, and for differences between perturbation composites across different monsoon and MJO regimes.

The test is applied on a gridcell by gridcell basis, with the false discovery rate limiting method (Wilks 2011, p. 178) used to address the repeated testing problem. Unless otherwise noted a significance level of $\alpha=0.05$ is used, with the false discovery rate limiting significance level $\alpha_{\mathrm{FDR}}$ reported in the figure captions. 


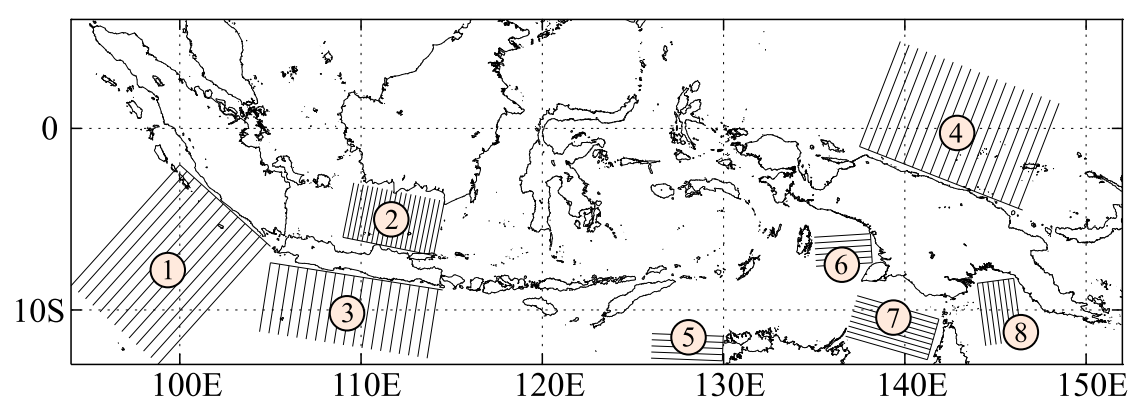

FIG. 2. Transects considered in this study: 1) southwest Sumatra, 2) south Java, 3 ) the Java Sea, 4) northwest New Guinea, 5) west Darwin, 6) Flamingo Bay, 7) the Gulf of Carpentaria, and 8) the Gulf of Papua.

Both scatterometer and precipitation radar data are also projected onto sets of transects emanating from coastlines of interest, then averaged over each set of transects. This allows diurnal cycles around particular coastlines to be identified more clearly. When transects are used it is no longer possible to identify a sample on which to apply a statistical hypothesis test; statistical significance is therefore estimated by projecting the $p$ values calculated for each grid cell onto the transects and averaging in an analogous way to the wind and precipitation data. Figure 2 shows the eight transects considered in this study. Transects 1-4 are the focus of section 3, which examines diurnal cycles of wind and precipitation, as these transects exhibit the most interesting relationships between the diurnal cycles of these two variables. Transects 5-8 are utilized in section 4 (see Fig. 16), which examines seasonal and intraseasonal variability in the diurnal wind cycles.

The generalization of the Hotelling $T^{2}$ from two groups to three or more is known as the MANOVA test. The MANOVA test is used in place of the Hotelling- $T^{2}$ to check where statistically significant differences exist between the CSCAT perturbations at different times of day-likewise for RSCAT. The false discovery rate limiting and transect methods are applied in the same way as for the Hotelling $T^{2}$ test, as described above.

\section{Diurnal cycles}

In this section, the transect method described in section 2d is applied to both RSCAT and CSCAT for four coastlines of interest. Figure 3 shows the results of projecting the CSCAT perturbation composites onto the transects shown in Fig. 2. Both the New Guinea and Sumatra transects show a mean diurnal cycle amplitude of $\approx 1 \mathrm{~m} \mathrm{~s}^{-1}$, whereas for south Java the amplitude is just over $0.5 \mathrm{~m} \mathrm{~s}^{-1}$. Along the Java Sea transects, the perturbations at 0500-0700 LST (1700-1900 LST) rapidly change sign $\approx 200 \mathrm{~km}$ north of Java, where land breezes (sea breezes) from the north coast of Java and south coast of Borneo converge (diverge). All the transects show evidence of the winds changing direction along the coastline before they change direction farther offshore, consistent with the propagation behavior predicted by linear theory for the tropics (Rotunno 1983, p. 2006). Statistically significant differences extend approximately 650,600 , and $400 \mathrm{~km}$ offshore for the New Guinea, Sumatra, and south Java transects, respectively, whereas the entire Java Sea region shows a statistically significant diurnal cycle.

Figure 4 shows the corresponding analysis for RSCAT. The amplitudes for New Guinea and the Java Sea are similar to CSCAT. The amplitudes for Sumatra and south Java are around $0.25 \mathrm{~m} \mathrm{~s}^{-1}$ greater, at $\approx 1.25$ and $\approx 0.75 \mathrm{~m} \mathrm{~s}^{-1}$, respectively. Statistically significant differences extend approximately 250, 400, and $220 \mathrm{~km}$ offshore for the New Guinea, Sumatra, and south Java transects, respectively. The reduced statistically significant offshore extents likely reflect the lower sample size of the RSCAT dataset and the increased variability in the perturbations that results from the necessarily coarser background winds (see section $2 b$ ).

To study how the diurnal cycles of surface wind and precipitation covary, Hovmöller diagrams of the surface wind perturbations and surface rain rates are considered. These can be constructed by viewing the composites formed for each time window as an estimate for the central time within that window. Figures $5 \mathrm{a}$ and $5 \mathrm{~b}$ are Hovmöller diagrams of the diurnal cycle of wind perturbations and total rain rate over the $\mathrm{Su}$ matra transects. Figure 5a is derived from RSCAT and GPM data, and Fig. 5b is derived from CSCAT and TRMM.

In both the RSCAT and CSCAT Hovmöller diagrams, the wind perturbations slant from the bottom left to the top right: evidence for propagation away from the coast. At least two propagation speeds are identifiable in each diagram, one between $\approx 200$ and $400 \mathrm{~km}$ offshore, 
CSCAT 29/10/2012 - 20/02/2014

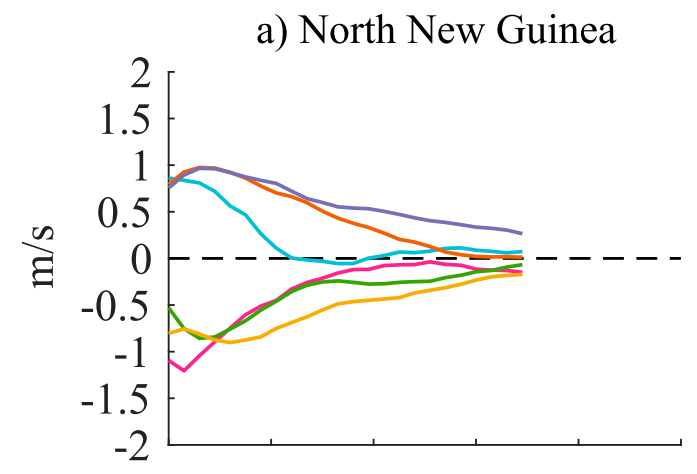

b) Southwest Sumatra
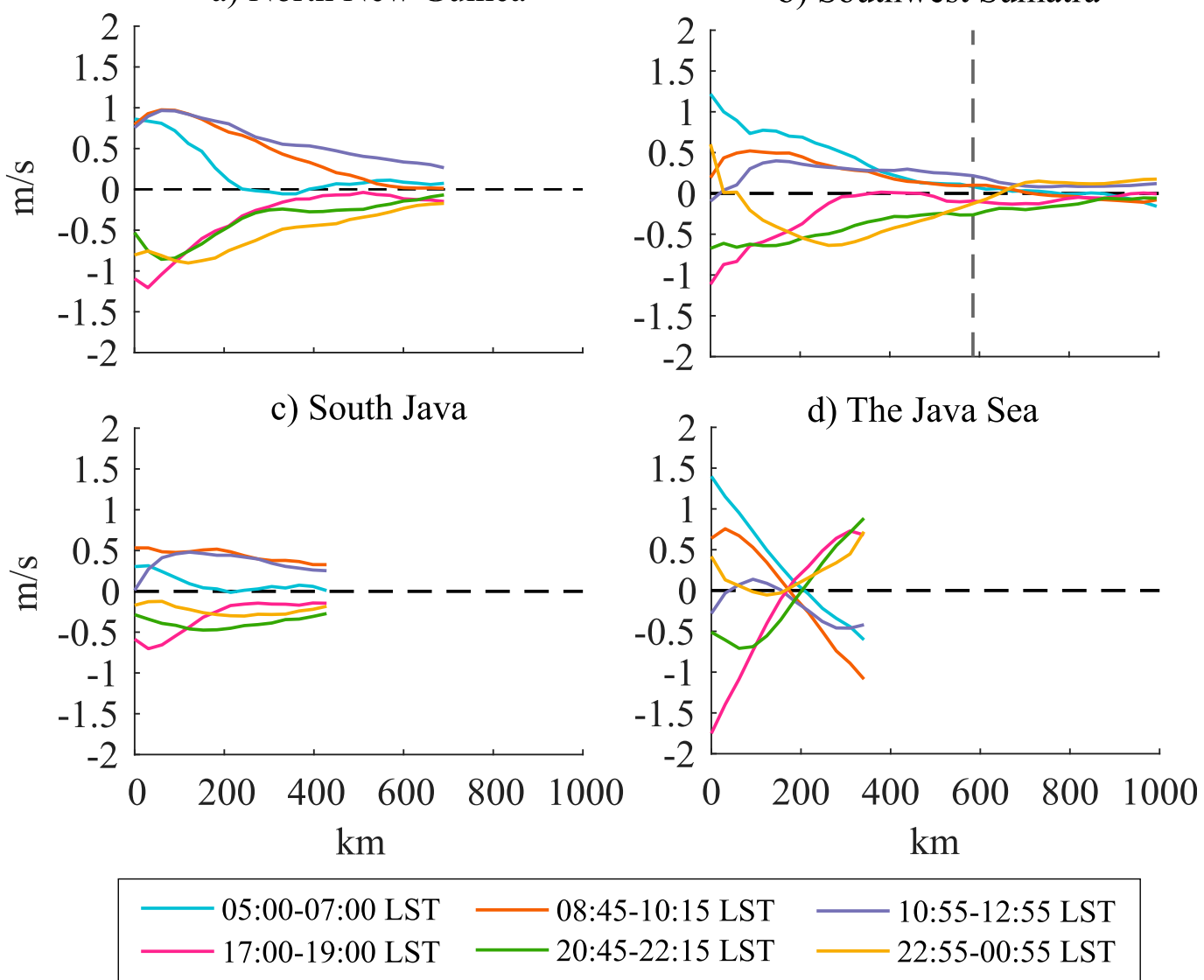

FIG. 3. CSCAT transect plots for the period between 29 Oct 2012 and 20 Feb 2014. Positive values indicate offshore wind perturbations (land breeze direction), negative values indicate onshore perturbations (sea breeze direction). Vertical lines provide an estimate of where statistically significant differences are no longer present using the method described in section $2 \mathrm{~d}$, with $\alpha=0.05$. The absence of a line indicates the entire transect shows significant differences.

and the other beyond $400 \mathrm{~km}$ offshore. Between 200 and $400 \mathrm{~km}$, the phase speed is $\approx 30 \mathrm{~m} \mathrm{~s}^{-1}$ for both RSCAT and CSCAT, with the estimate more ambiguous for CSCAT. At distances greater than $400 \mathrm{~km}$ there is a nonpropagating diurnal cycle, with the CSCAT signal again less obvious. A third slower propagation speed has been also been marked near the coast; this signal propagates at $\approx 8 \mathrm{~m} \mathrm{~s}^{-1}$, although this estimate is not precise.

Both diagrams show similar features in the timing of offshore precipitation, although the GPM estimates are higher than those for TRMM. In both cases, the second highest precipitation contour of $0.5 \mathrm{~mm} \mathrm{~h}^{-1}$ overlaps both offshore and onshore wind regimes. In the case of RSCAT/GPM, the peak precipitation contour close to the coast actually occurs at the point of transition between onshore and offshore winds, and the $0.5 \mathrm{~mm} \mathrm{~h}^{-1}$ shaded region remains mostly in this transition zone. The CSCAT/TRMM diagram, however, shows the peak precipitation contour overlapping the offshore wind regime more than with RSCAT/GPM. Note that statistically significant diurnal cycles in the TRMM and GPM data across the Maritime Continent-as determined by the Mann-Whitney test (Hollander et al. 2014) - are generally only detectable up to $200 \mathrm{~km}$ offshore for the TRMM and GPM data used in this analysis (results not shown).

Figures $6 \mathrm{a}$ and $6 \mathrm{~b}$ present the RSCAT/GPM and CSCAT/TRMM Hovmöller diagrams for the south Java transects, respectively. The timing of the surface wind diurnal cycle is similar between the diagrams, although the amplitude is $\approx 0.2 \mathrm{~m} \mathrm{~s}^{-1}$ greater for RSCAT. As before, the diagrams show a slower propagation speed close to the coast that becomes faster with distance 
RSCAT 10/04/2014 - 18/08/2016
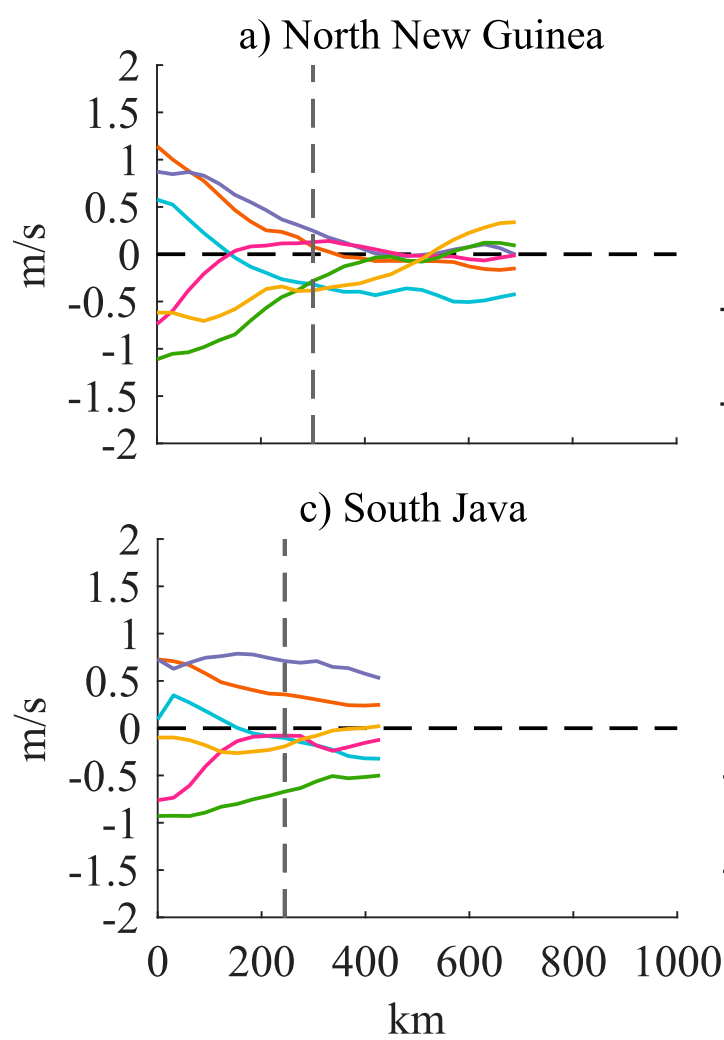

b) Southwest Sumatra

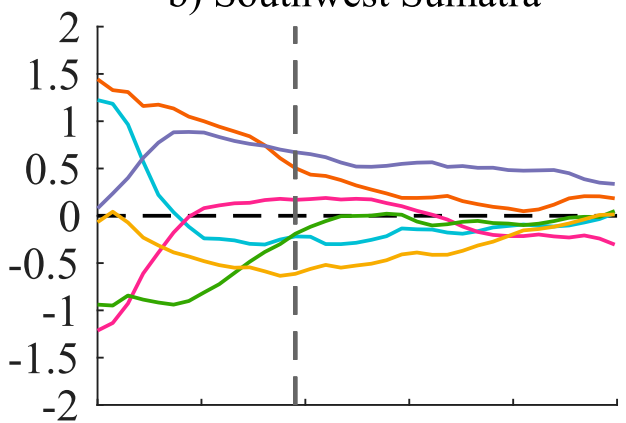

d) The Java Sea

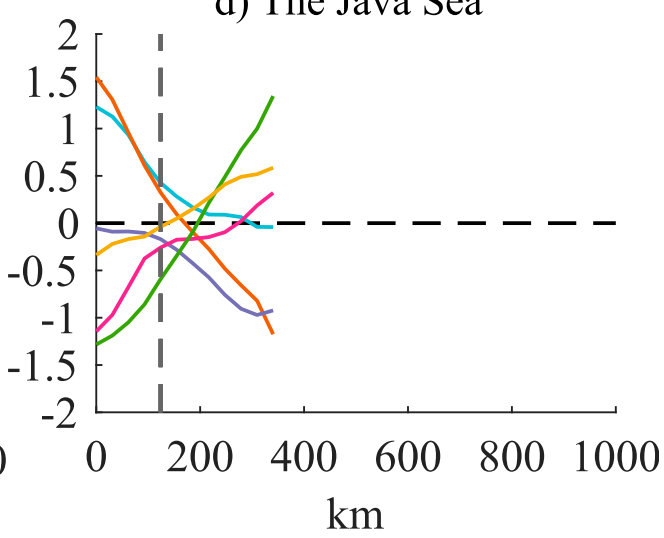

02:00-06:00 LST -06:00-10:00 LST

10:00-14:00 LST

14:00-18:00 LST 18:00-22:00 LST 22:00-02:00 LST

FIG. 4. As in Fig. 3, but for the RSCAT transect plots over the period between 10 Apr 2014 and 18 Aug 2016. Note that the colors used here are for different times than in Fig. 3.

offshore. In the first $\approx 200 \mathrm{~km}$ the propagation speeds for both RSCAT and CSCAT are $\approx 10 \mathrm{~m} \mathrm{~s}^{-1}$; beyond $100 \mathrm{~km}$ the speeds are again $\approx 30 \mathrm{~m} \mathrm{~s}^{-1}$. Both Hovmöller diagrams show the offshore winds peaking between 0800 and $1200 \mathrm{LST}$, but the onshore winds peaking between 1600 and 2000 LST, indicating that in this region the diurnal cycle is not symmetric. It is unclear whether the precipitation is actually propagating away from the coast in this case-particularly with GPM.

Figures $6 \mathrm{c}$ and $6 \mathrm{~d}$ show the Hovmöller diagrams for the Java Sea transects, which are more complex than the former Hovmöller diagrams. The Java Sea transects begin at the north coast of Java and extend northerly to the south coast of Borneo; the south Borneo offshore winds therefore appear as onshore winds in these diagrams, and vice versa for the south Borneo onshore winds. Both RSCAT and CSCAT agree on timing, with the offshore winds on the north coast of Java and the south coast of Borneo peaking between $0400-0800$ and 0800-1200 LST, respectively, and the onshore winds between 1600-2000 and 2000-2400 LST, with the RSCAT signal closer to 2000 LST.

Propagation speeds are difficult to estimate for the Java Sea cross section, as the transects are short. For RSCAT, the Borneo land-breeze-shaded region arguably shows two propagation speeds: one closer to the coast at $\approx 5 \mathrm{~m} \mathrm{~s}^{-1}$, the other farther offshore at $\approx 25 \mathrm{~m} \mathrm{~s}^{-1}$. The north Java sea breeze shows some propagation at around $30 \mathrm{~m} \mathrm{~s}^{-1}$. For CSCAT, the Java and Borneo land breezes, as well as the Java sea breeze exhibit some propagation behavior with speeds at $\approx 25 \mathrm{~m} \mathrm{~s}^{-1}$.

The GPM contours show precipitation peaking at the point of convergence between the offshore winds from Java and Borneo, with the arching shape of the contours suggesting precipitation may also be propagating away from the coasts. The TRMM Hovmöller shows similar propagation behavior, although it is unclear from the $0.5 \mathrm{~mm} \mathrm{~h}^{-1}$ contour precisely where peak precipitation occurs. Figure 7 shows the TRMM precipitation data 


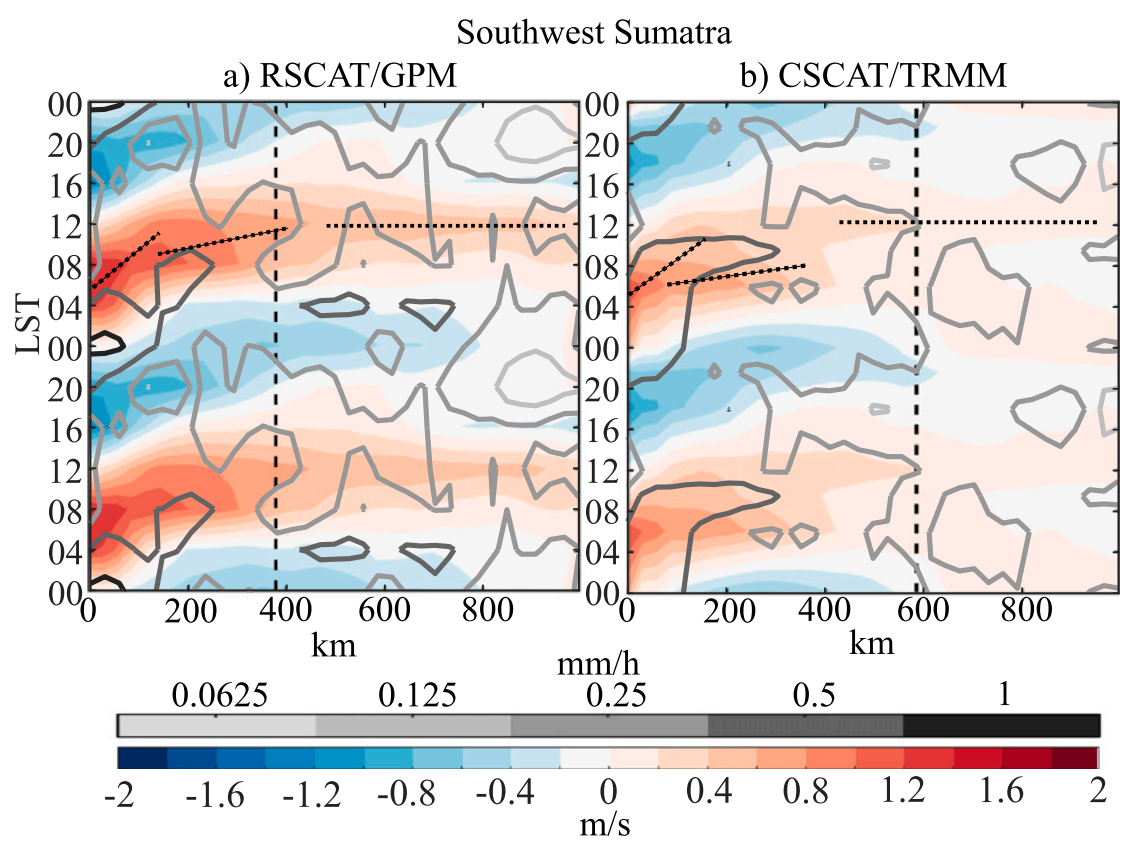

FIG. 5. Hovmöller diagrams for (a) RSCAT/GPM and (b) CSCAT/TRMM over southwest Sumatra (transect 1 in Fig. 2). Shading provides wind perturbation speed with red and blue shading indicating offshore (land breeze) and onshore (sea breeze) perturbations, respectively. Fine dotted lines provide subjective estimates of propagation speed, and the vertical coarse dotted lines indicate how far offshore statistically significant perturbations can be detected. Contours give the precipitation rates from TRMM and GPM.

over each time interval; it indicates that the heaviest precipitation indeed occurs near the center of the Java Sea. This is in contrast to the Sumatra and south Java cases, where the maximum precipitation is found near the coast.

Figure 8 shows the RSCAT and CSCAT Hovmöller diagrams for the north New Guinea transects. Two distinct propagation speeds are arguably identifiable in both the RSCAT and CSCAT diagrams. In the first $200 \mathrm{~km}$ from the coast the propagation speeds for RSCAT and CSCAT are $\approx 10$ and $15 \mathrm{~m} \mathrm{~s}^{-1}$, respectively; farther offshore these increase to $\approx 30$ and $\approx 50 \mathrm{~m} \mathrm{~s}^{-1}$. Both the GPM and TRMM precipitation contours align with the offshore winds, but precipitation peaks slightly earlier in the GPM data than in the TRMM data.

Figures 9 and 10 provide comparisons of the WRF and CSCAT perturbation composites over the time period where data for both are available (i.e., from 1 December 2012 to 28 February 2013, and 1 December 2013 to 20 February 2014) - there was insufficient RSCAT data to include RSCAT in this comparison. In both cases the CSCAT composites are less coherent than in Figs. 5 and 8, likely reflecting the reduced sampled sizes. Furthermore, in both cases the WRF land-sea breezes are up to $1 \mathrm{~m} \mathrm{~s}^{-1}$ faster and initiate 2$4 \mathrm{~h}$ earlier than in CSCAT.

Figure 11 shows WRF and ASCAT perturbation composites over the three austral summers between 2012 and 2015 for the southwest Sumatra and north New Guinea transects. For this comparison, two methods of calculating the WRF perturbation composites are considered. In both methods the WRF data are first binned into a grid with the same spatial and temporal resolution as ASCAT $\left(25^{\circ}\right.$ latitude and longitude, $90 \mathrm{~min}$ ). The WRF-Complete perturbation composites are calculated using all the available WRF data; the WRF-Restricted perturbation composites are calculated by first discarding WRF data wherever there are not corresponding ASCAT data. This means that the WRF-Restricted morning and evening perturbation composites are symmetric for the same reason as the ASCAT perturbation composites (see section 2c.) Note that the WRF-Complete composites are not symmetric: the WRF-Complete land breezes are between 0.5 and $1.0 \mathrm{~m} \mathrm{~s}^{-1}$ faster than the WRF-Complete sea breezes. This asymmetry between land and sea breezes is consistent with the modeling work of Qian et al. (2012), who showed that sea-breeze density currents can be blocked by the presence of topography, 


\section{South Java}

a) RSCAT/GPM

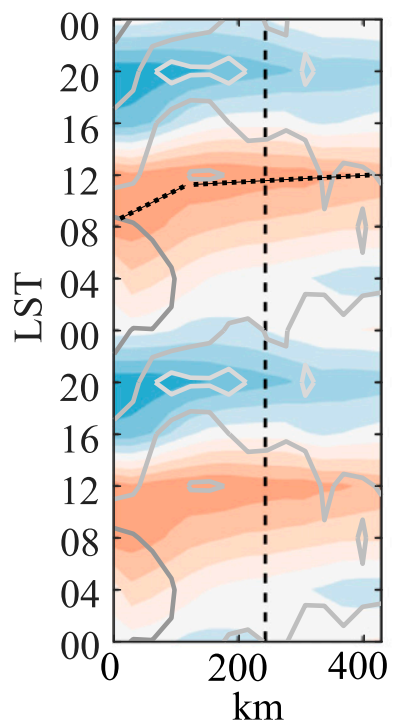

b) CSCAT/TRMM

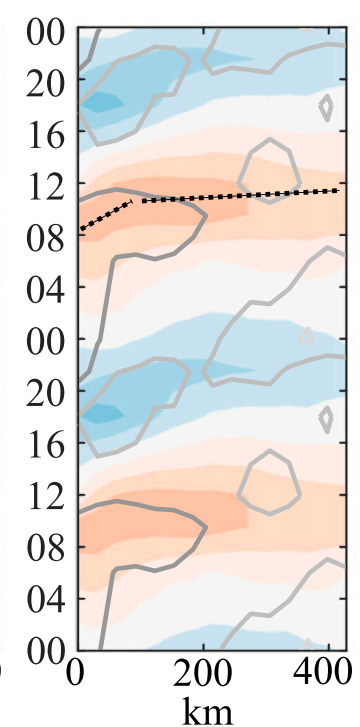

The Java Sea

c) RSCAT/GPM d) CSCAT/TRMM
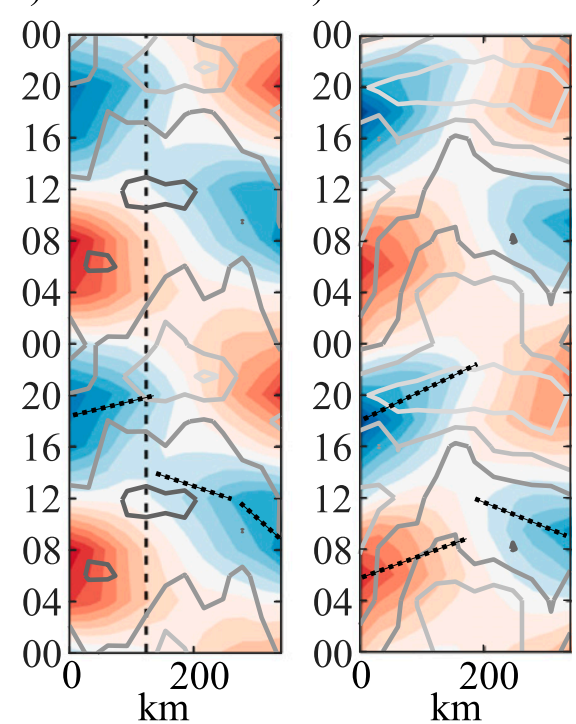

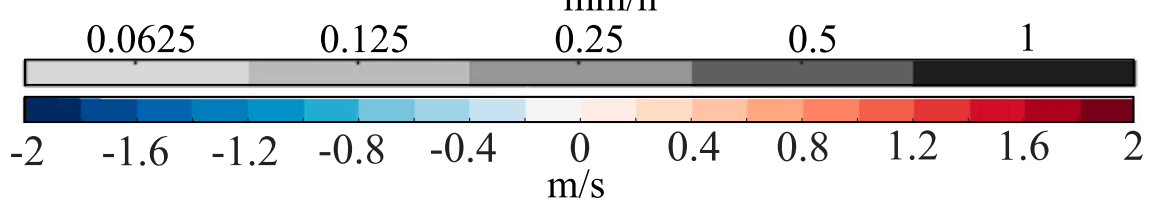

FIG. 6. Hovmöller diagrams for (a),(c) RSCAT/GPM and (b),(d) CSCAT/TRMM over (left) south Java (transect 2 in Fig. 2) and (right) the Java Sea (transects in Fig. 2), respectively. Shading, contours, and dotted lines are as in Fig. 5.

leading to cool air pooling between the topography and the coast, which then strengthens subsequent land-breeze density currents.

Both the WRF-Complete and WRF-Restricted perturbations in southwest Sumatra are up to $1 \mathrm{~m} \mathrm{~s}^{-1}$ faster than those for ASCAT; furthermore, the WRF morning (evening) perturbations start changing direction by 0845-1015 (2045-2215) LST, whereas the ASCAT perturbations do not, again suggesting a timing bias in
WRF. Analogous results hold for north New Guinea, although the timing bias in this region is more pronounced, as close to the coast the ASCAT and WRF perturbations are of opposite sign.

Vincent and Lane (2016a, 2017) showed that the WRF precipitation diurnal cycle occurred $\approx 3$ hours earlier, and was up to twice as intense as satellite precipitation observations. If the diurnal cycle of offshore precipitation is indeed associated with the gravity wave

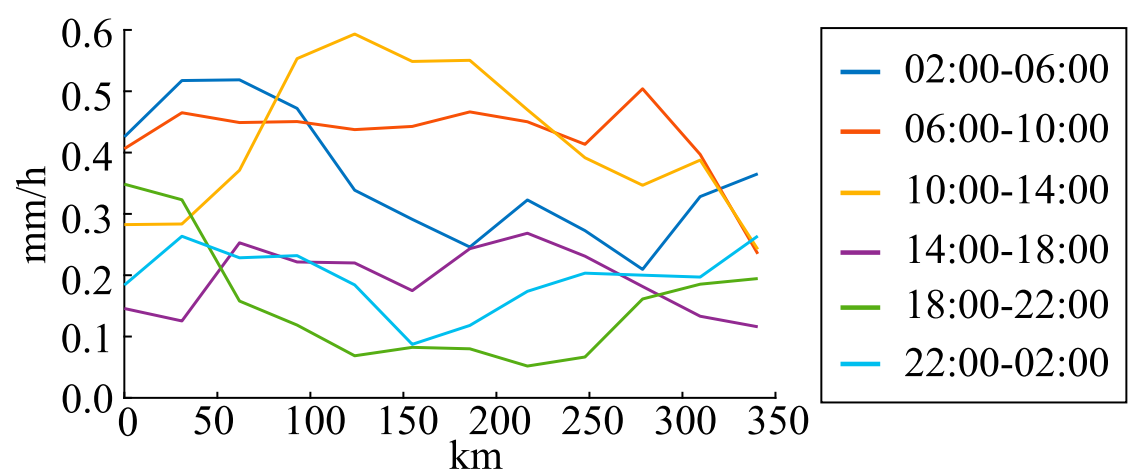

FIG. 7. TRMM mean precipitation over the Java Sea (transect 3 in Fig. 2.) 


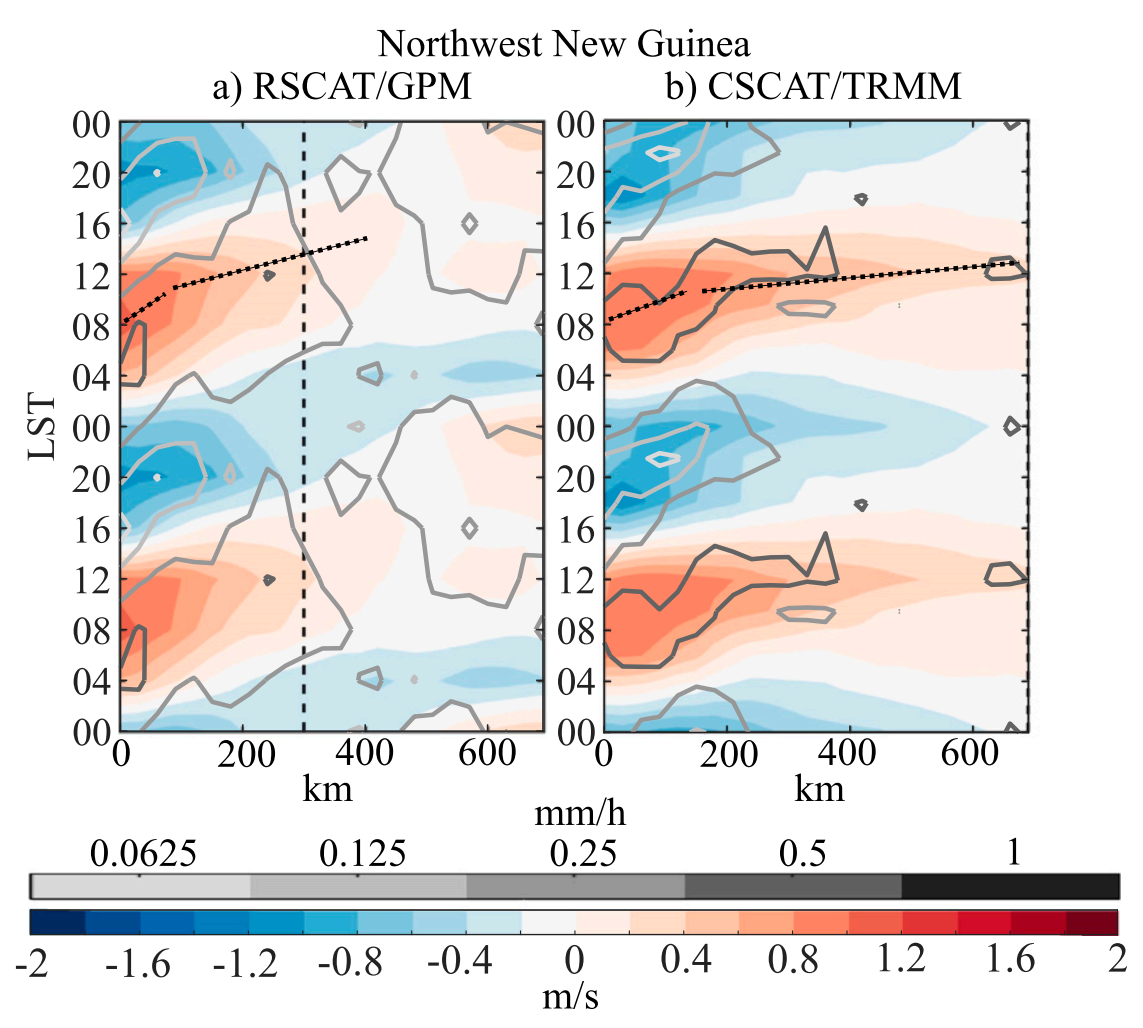

FIG. 8. Hovmöller diagrams for (a) RSCAT/GPM and (b) CSCAT/TRMM over north New Guinea (transect 4 in Fig. 2.) Shading, contours, and dotted lines are as in Fig. 5.

propagation behavior of the land-sea breeze-as they suggest - then the land-sea breeze timing and intensity biases present in Figs. 9, 10, and 11 may provide a partial explanation for WRF's diurnal precipitation biases.

\section{Seasonal and intraseasonal variability}

This section presents results on the seasonal and intraseasonal variability of the diurnal cycle of surface winds. Figure 12 shows the mean winds, as observed by ASCAT, across the Maritime Continent for the four combinations of season and MJO phase. The Australian monsoon period of November-April is characterized by northeasterly flow north of the equator that turns and then flows northwesterly to westerly south of the equator. During MJO active periods winds north of the equator are weaker, but stronger south of the equator, particularly between the islands of Java, Borneo, and Sulawesi. During the Asian monsoon period of May-October, the winds flow in roughly the opposite direction. The winds are stronger south of the equator compared to the Australian monsoon, and stronger again during the inactive phase of the MJO. North of the equator, they generally flow southerly to southwesterly, although during the inactive phase of the MJO a weak mean southeasterly to easterly flow is retained north of the equator between $140^{\circ}$ and $150^{\circ} \mathrm{E}$.

Figure 13 shows the NOAA satellite observed outgoing longwave radiation (OLR) data composited over the four seasonal/MJO regimes. Lower OLR values indicate greater cloud cover, and are used here as a proxy for convection. During the Australian monsoon months of November-April, the majority of the convection occurs along the band between $5^{\circ} \mathrm{N}$ and $10^{\circ} \mathrm{S}$. The OLR is $\approx 20 \mathrm{~W} \mathrm{~m}^{-2}$ lower in the active phase than the inactive phase throughout most of this region, capturing the increased convection as the MJO moves through the Maritime Continent. During the Asian monsoon, the bulk of the convection occurs north of the equator, with convection increasing in this region during the active phase of the MJO.

Figure 14 shows the wind perturbations across the same four seasonal/MJO regimes for the 0845-1015 LST time window-recall from section $2 b$ that when only ASCAT data are used, the 2045-2215 LST perturbation composites are an almost perfect symmetric copy of those at 0845-1015 LST. Differences can be seen between the Australian monsoon and Asian monsoon panels, with the Asian monsoon producing stronger wind anomalies in Flamingo Bay, the Gulf of Carpentaria, and north of Darwin (see Fig. 1 for a map of these locations.) These differences are statistically 


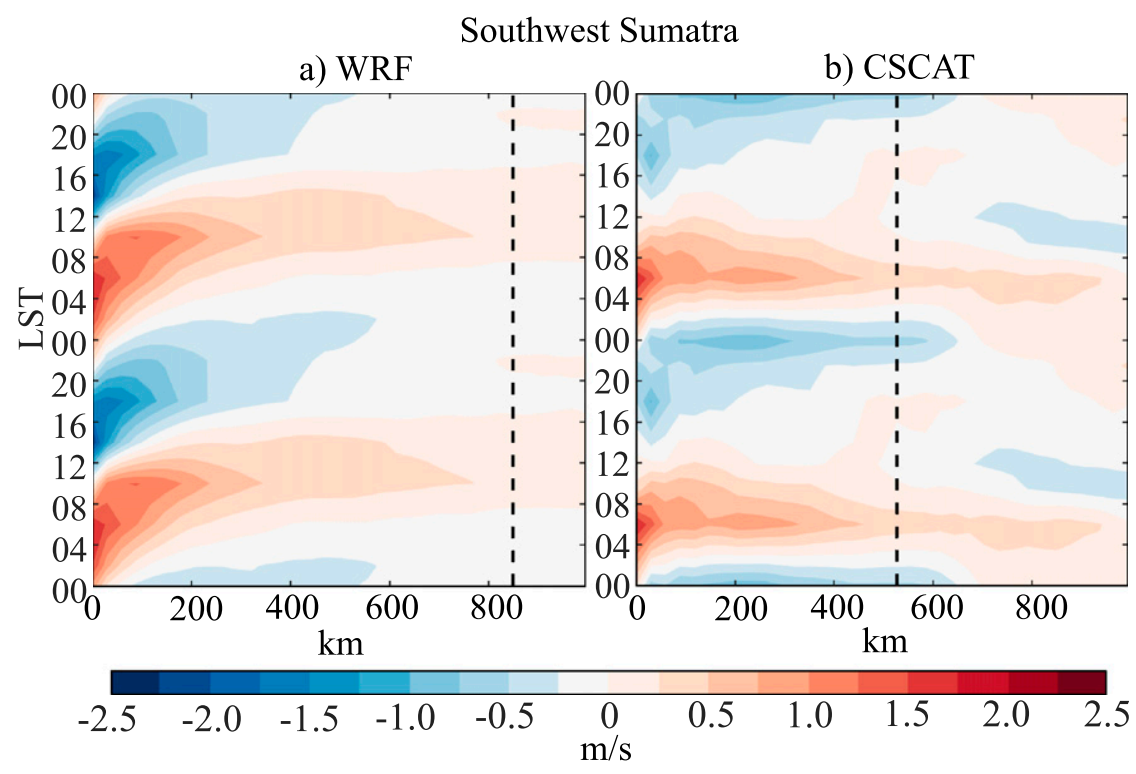

FIG. 9. (a) WRF and (b) CSCAT winds over southwest Sumatra (transect 1 in Fig. 2). Shading and dotted lines are as in Fig. 5.

significant almost everywhere that the perturbations themselves are statistically significant.

Differences between MJO phases within each monsoon regime are less clear. Rauniyar and Walsh (2011) argued that during the MJO active phase, there is greater cloud cover over the Maritime Continent, which reduces the surface heating and results in less contrast between land and sea surface temperatures and hence weaker land-sea breezes. However, Fig. 14 indicates that during the Australian monsoon, when the MJO is active, perturbations are actually stronger in the Gulf of Papua and the Makassar Strait. By contrast, during the MJO inactive phase, stronger perturbations are present in the Gulf of Carpentaria and the Strait of Malacca, in accordance with the hypothesis of Rauniyar and Walsh (2011).

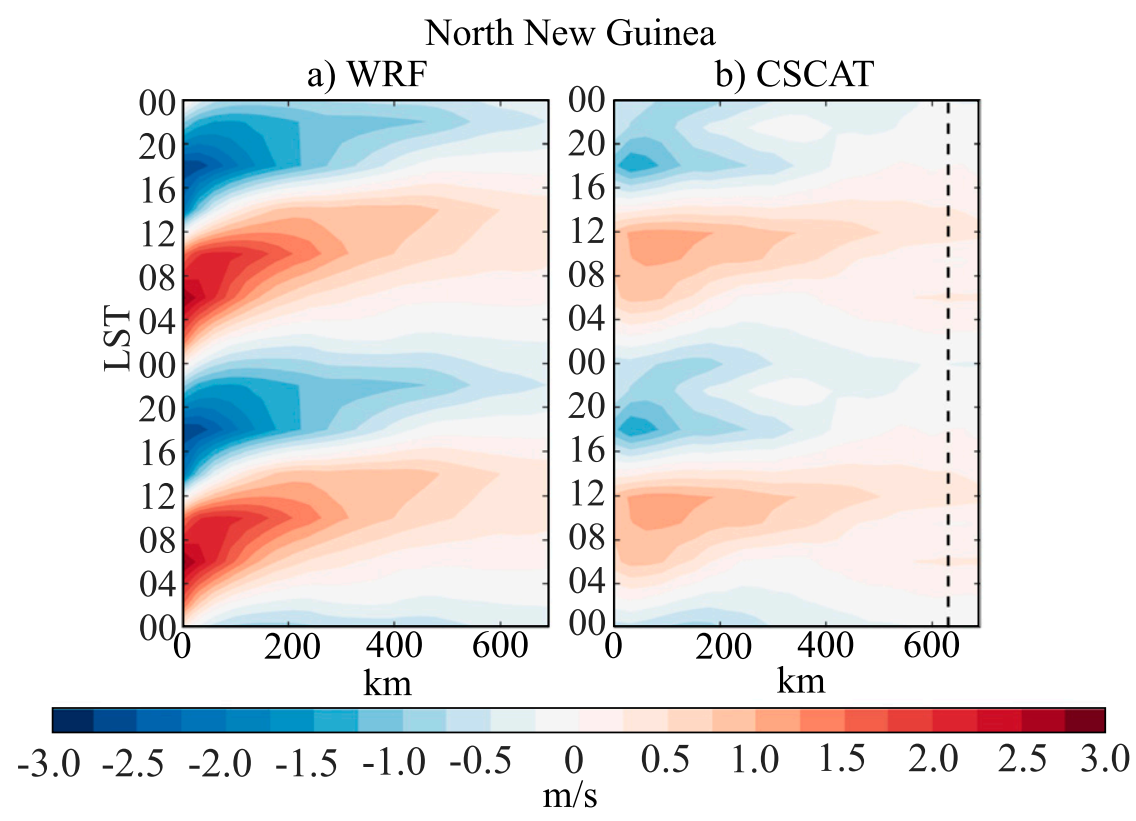

FIG. 10. (a) WRF and (b) CSCAT over transect north New Guinea (transect 4 in Fig. 2). Shading and dotted lines are as in Fig. 5. 
WRF and ASCAT Austral Summers 2012 - 2015

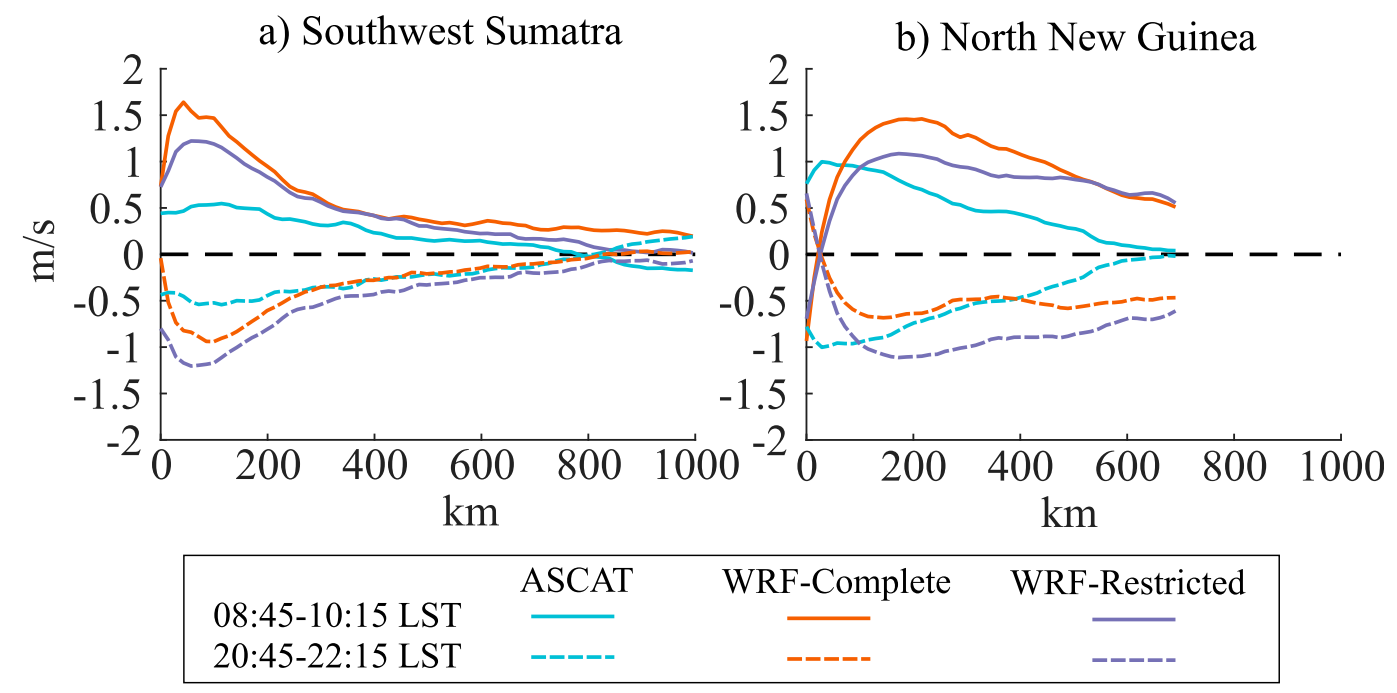

FIG. 11. Perturbation composites projected onto the transects shown in Fig. 2. Blue, orange, and purple lines provide the ASCAT, WRF-Complete, and WRF-Restricted perturbation composites, respectively. The WRFRestricted perturbations are calculated by first restricting the WRF dataset to where ASCAT data exists, whereas the WRF-Complete perturbations use all available WRF data. Solid and dashed lines provide the morning (08451015 LST) and evening (2045-2215 LST) perturbations respectively.

Figures $15 \mathrm{a}$ and $15 \mathrm{~b}$ provide comparison plots for the differences between MJO active and inactive phases during the Australian monsoon season to better reveal subtle differences between them. The mean wind comparison shows the northeasterlies flowing up to $3 \mathrm{~m} \mathrm{~s}^{-1}$ faster to the northwest of Borneo, and the northeasterlies up to $4 \mathrm{~m} \mathrm{~s}^{-1}$ faster between Sulawesi and Java, and up to $5 \mathrm{~m} \mathrm{~s}^{-1}$ faster to the northeast of New Guinea. Figure $15 \mathrm{c}$ shows that statistically significant differences in the wind perturbations are generally only found in fewer than ten regions of the domain, noting the stringent significance level $\alpha_{\mathrm{FDR}}=0.0012$ imposed by the false discovery rate limiting method. This lack of statistically significant differences in the sea-breeze circulation across the majority of the Maritime Continent is consistent with the modeling results of Vincent and Lane (2016a, 2017).

Note that in the Gulf of Papua, the background winds are onshore during the inactive phase, but offshore in the active phase, with the perturbations stronger during the active phase. The opposite is true for the eastern part of the Gulf of Carpentaria, where the background winds are onshore during the active phase, but offshore during the inactive phase, with the perturbations now stronger in the inactive phase. Analogous observations apply to Flamingo Bay. Figures 12 and 14 indicate that similar trends can be identified when comparing the Australian monsoon and Asian monsoon winds, that is, the stronger perturbations tend to occur in whichever season has stronger (weaker) offshore (onshore) background winds (e.g., the Gulfs of Papua and Carpentaria, the eastern part of Flamingo bay, the Makassar Strait, and the western side of northern Australia).

Figure 16 shows the relationship between the background wind speed and the maximum perturbation wind speed for the eight transects shown in Fig. 2. The Australian monsoon season and active and inactive MJO phases, and the Asian monsoon season active MJO phase are considered-the Asian monsoon season inactive MJO phase results are almost identical to those for the active phase. Background winds are calculated by averaging over the transects, and for both the background and perturbation winds only the components perpendicular to the coast are considered. Of the transects 1-4 considered in section 3 , only the Java sea transects show significant amplitude variability with season, suggesting the results of section 3 are generally representative of wind perturbations throughout the year. Overall, the amplitude of the perturbation composites increases as the component of the background wind perpendicular to the coast goes from negative (onshore) to positive (offshore). This trend is also evident when the Australian and Asian monsoon results are considered separately.

\section{Discussion}

Section 3 showed that the land-sea breeze perturbations across the Maritime Continent have mean 

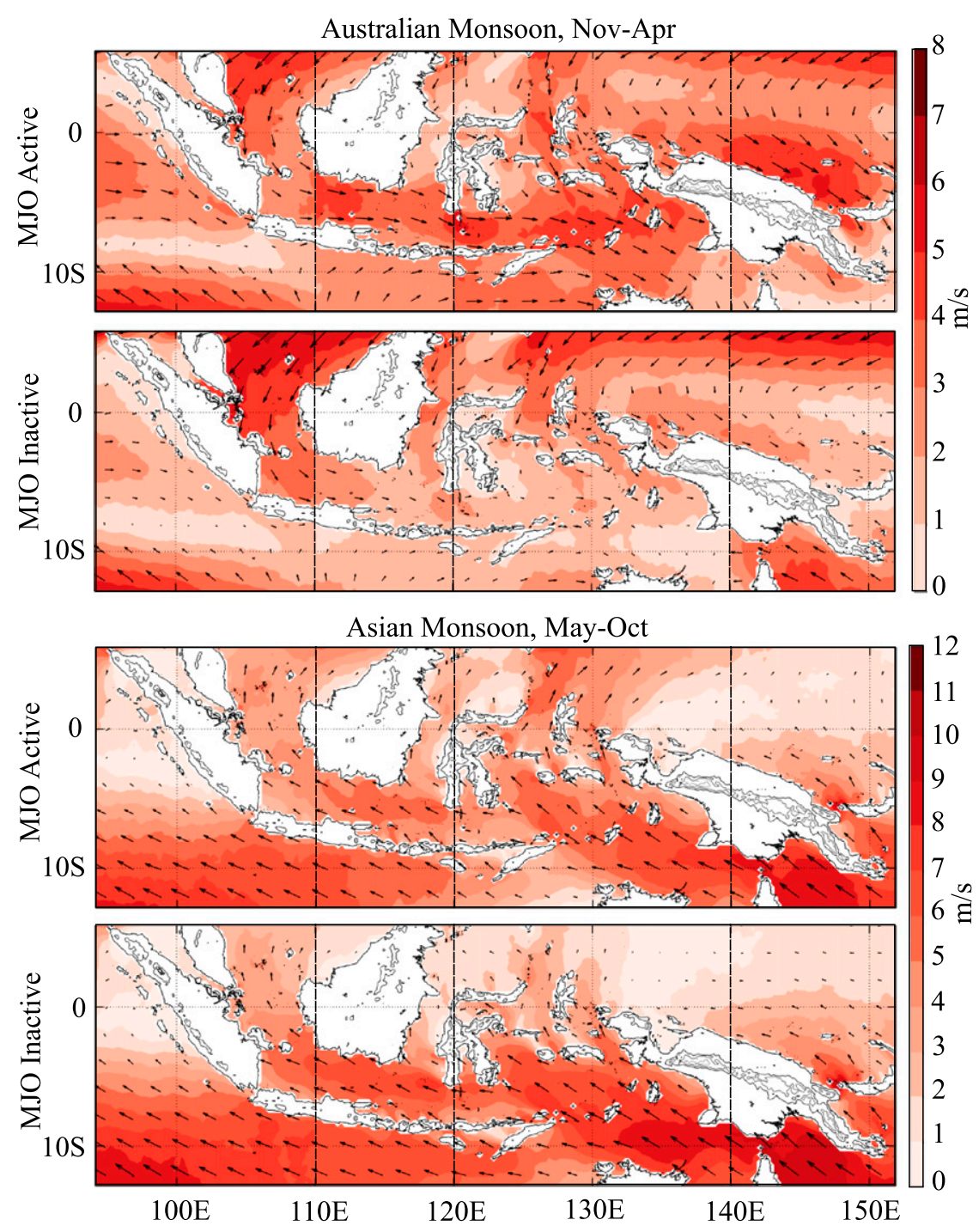

FIG. 12. ASCAT mean wind composites during the Australian monsoon season (November-April), and Asian monsoon season (May-October) between 2012 and 2017. Each season is further divided into MJO active and inactive regimes, with vertical lines indicating discontinuities in how these regimes are defined. Shading and vectors provide wind speeds and directions, respectively.

amplitudes of between 1 and $2 \mathrm{~m} \mathrm{~s}^{-1}$, and propagate at different speeds with distance from the coast (see Table 3 for a summary of these results.) Vincent and Lane (2016a) and Hassim et al. (2016) each identified two distinct propagation speeds for the land-sea breeze in their WRF simulations of New Guinea: they attributed the slower and faster propagation speeds to density current and gravity wave dynamics, respectively.

In the results of section 3, the slowest propagation speeds are between 5 and $15 \mathrm{~m} \mathrm{~s}^{-1}$, which occur within the first $200 \mathrm{~km}$ from the coast. These speeds are consistent with the theory of density currents and similar to those found in numerical studies (e.g., Robinson et al.
2013; Liu and Moncrieff 1996; Igel et al. 2018). However, other studies have identified gravity waves with short vertical wavelengths propagating at similar speeds (e.g., Tulich and Mapes 2008; Moncrieff and Lane 2015). The analyses shown in Vincent and Lane (2016a) suggest that (at least in the modeling studies) these slower signals near the coast have vertical structure consistent with density currents. Moreover, the termination of these slow signals within $200 \mathrm{~km}$ of the coast is also consistent with a density current instead of a gravity wave.

In the results of section 3, faster propagation speeds of between 25 and $50 \mathrm{~m} \mathrm{~s}^{-1}$ are detectable between 200 and $400 \mathrm{~km}$ from the coast. These signals are consistent with 


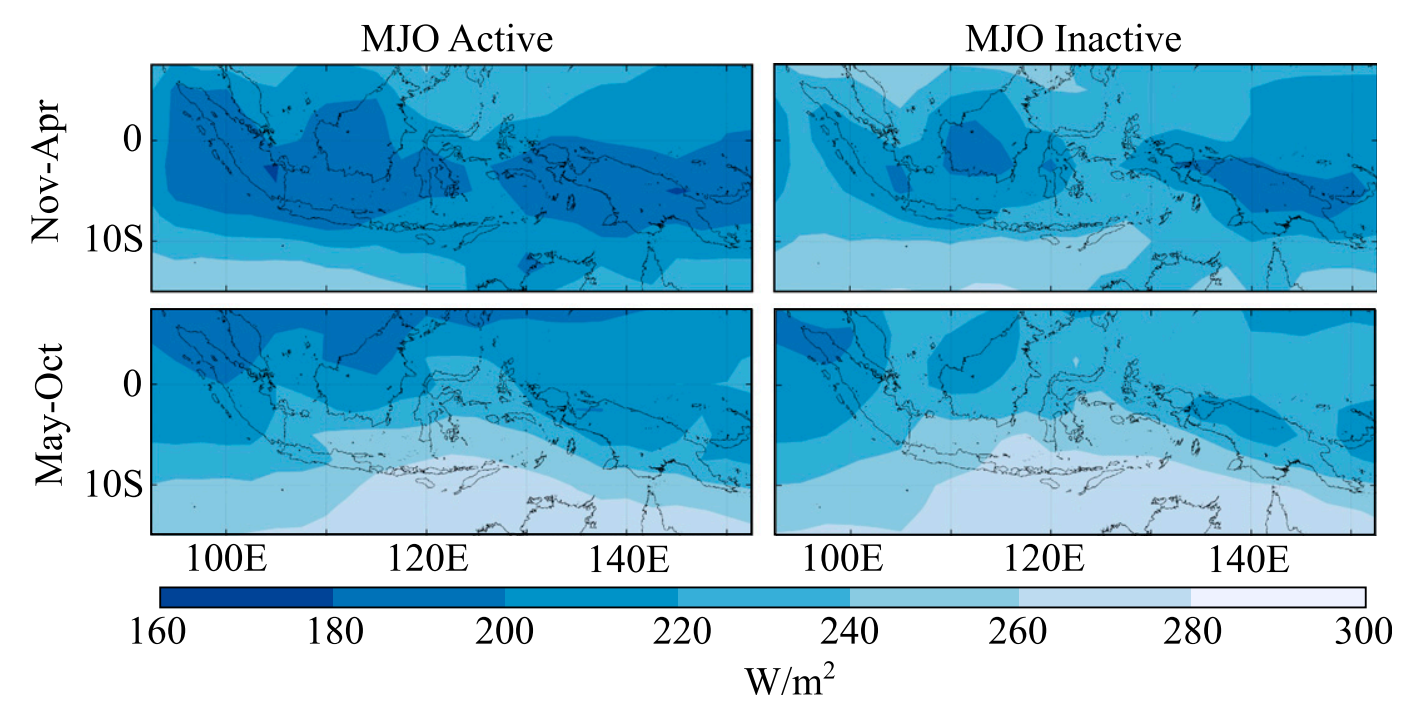

FIG. 13. Composites of NOAA satellite observed OLR data across each seasonal/MJO regime.

the Rotunno (1983) theory that tropical land and sea breezes propagate away from coastlines as gravity waves. Note that if gravity waves are present, gravity wave propagation would also be occurring in the first $200 \mathrm{~km}$ from the coast. The overall signal would then represent the superpositioning of both mechanisms, with density current dynamics dominant near the coast and gravity wave dynamics dominant farther offshore.

Note that convective heating also generates gravity waves, so diabatic heating from convection over land may also contribute to the propagating signals identified in section 3, as discussed by Love et al. (2011) and Hassim et al. (2016). However, Vincent and Lane (2017) assessed diurnal cycles of surface wind perturbations around Sumatra and New Guinea using a numerical model of the Maritime Continent that spanned 10 austral summers, and found that the perturbations were only minimally affected by MJO phase, despite variability in the diurnal cycles of convection over land. This suggests that surface heating, and hence the land-sea breeze, is likely the dominant source of the propagating signals in section 3-at least for Sumatra and New Guinea-but further research into this topic is warranted.

The propagation speeds reported in Table 3 are consistent with those found by Vincent and Lane (2016a) for the WRF Model, except that the CSCAT propagation speed north of New Guinea is faster than that of WRF. The New Guinea CSCAT sea-breeze-shaded regions are erratic, with a stationary signal occurring at around midnight. Recall that during the time period 2355-0055 LST CSCAT data are based on the OSCAT dataset, and Moroni et al. (2013, their Fig. 4) showed that there are strong easterly zonal wind biases in the OSCAT scatterometer winds north of New Guinea. These biases are likely the reason for the anomalously fast CSCAT landsea breeze propagation speed.

The Sumatra Hovmöller diagrams in Fig. 5 show that a third signal can be identified at distances greater than $400 \mathrm{~km}$ from the coast. This signal likely represents an open-ocean diurnal cycle unrelated to coastal processes, possibly due to afternoon boundary layer instability (Dai and Deser 1999). This open-ocean diurnal cycle could also be combining with the gravity wave signal in the south Java and New Guinea cases, producing the apparent smooth transition from slower to faster propagation speeds.

The Sumatra Hovmöller diagrams also show that propagating diurnal signals in precipitation are confined to the first $300 \mathrm{~km}$ from the coast. It is difficult to discern a single propagation speed for the precipitation in these results: it may be estimated to lie between 10 and $30 \mathrm{~m} \mathrm{~s}^{-1}$. In the case of GPM, the heaviest precipitation contours align with the transition from sea breeze to land breeze; in the case of TRMM they align more with the land breeze. This timing is consistent with the results of Kilpatrick et al. (2017) for the Bay of Bengal.

Mori et al. (2004) studied offshore propagation of rainfall around Sumatra using TRMM precipitation radar composited over the years 1998-2000. The rainfall propagation speeds southwest of Sumatra they obtained were $\approx 10 \mathrm{~m} \mathrm{~s}^{-1}$ for the first $100 \mathrm{~km}$, then over $30 \mathrm{~m} \mathrm{~s}^{-1}$ for the next $300 \mathrm{~km}$. Just offshore, rainfall peaked between 0400 and 0700 LST. These results share both similarities and differences with those of Fig. 5. Both the TRMM and GPM diagrams show offshore propagation $\approx 300 \mathrm{~km}$ offshore, comparing favorably to Mori et al. The intensity of the precipitation is also similar, peaking between $0.5-1 \mathrm{~mm} \mathrm{~h}^{-1}$. However, the 

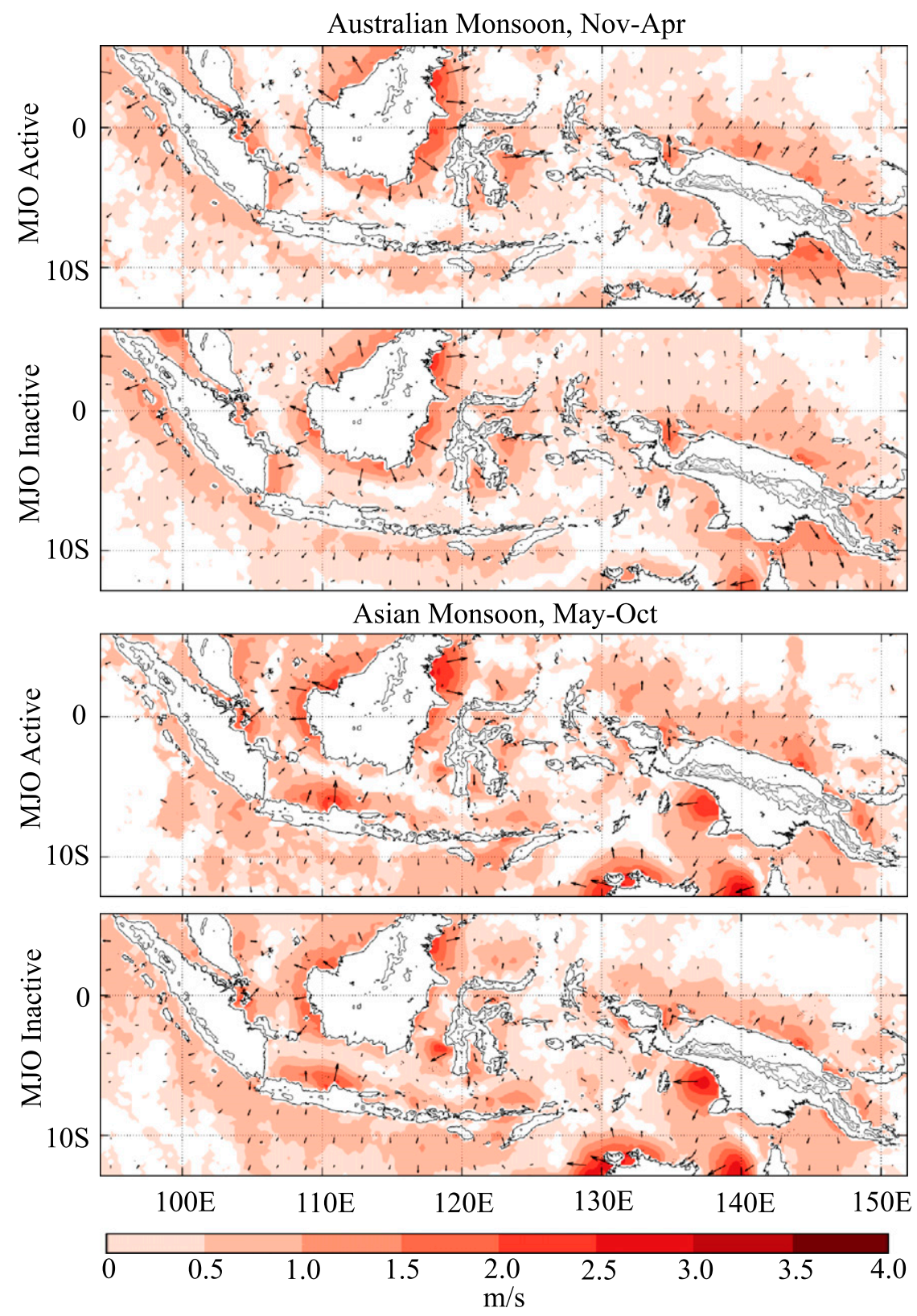

FIG. 14. As in Fig. 12, but for the 0845-1015 perturbation composites across the four seasonal/MJO regimes. White regions indicate that where there is no statistically significant difference between the 0845-1015 and 2045-2215 perturbation composites.

GPM precipitation just offshore peaks earlier at around midnight. Although the timing of the peak precipitation for TRMM is not detectable in this Hovmöller diagram, time series (not shown) indicate that it too peaks at around midnight, and so both TRMM and GPM show peak rainfall occurring at least $4 \mathrm{~h}$ earlier than in the results of Mori et al. In terms of the propagation speed of the precipitation signal, Mori et al's results are qualitatively closer to those of TRMM than GPM, with a slower speed closer to the coast and a faster one farther offshore. However, in the results of Mori et al. the actual speed of propagation close to the coast is nearer to that of GPM at $\approx 8 \mathrm{~m} \mathrm{~s}^{-1}$ compared to that of TRMM at $\approx 4 \mathrm{~m} \mathrm{~s}^{-1}$. These differences are likely due to the coarse temporal bin size necessary for this study, and the different time period studied by Mori et al.

Rauniyar and Walsh (2011) examined the rainfall diurnal cycle throughout the Maritime Continent using 

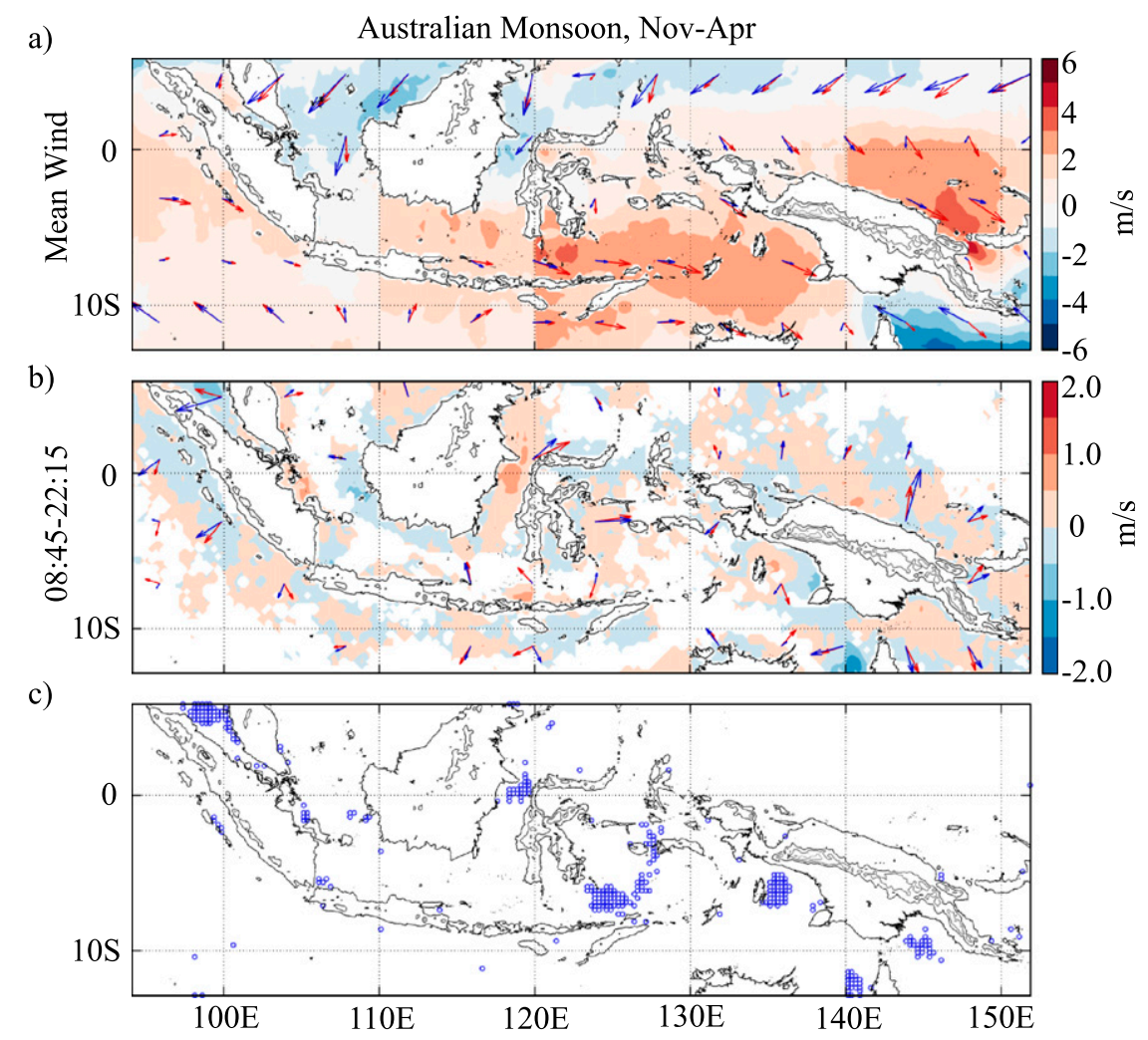

FIG. 15. Comparison between the Australian monsoon MJO active and MJO inactive regimes. Shading provides wind speeds of (a) the mean winds and (b) the wind perturbation composites, during the MJO active regime, minus those of the MJO inactive regime; red and blue vectors provide the wind direction during active and inactive regimes, respectively. (c) Statistically significant differences between perturbation composites are shown. Statistical significance tested using the Hotelling $T^{2}$ test and false discovery rate limiting method; $\alpha_{\mathrm{FDR}}=0.0012$.

10 years of TRMM precipitation radar data over the years 1998-2008. The results from their transect analysis of Sumatra agree well with those of GPM in Fig. 5, with a propagation speed of $\approx 8 \mathrm{~m} \mathrm{~s}^{-1}$. Also, the precipitation peaks just offshore between 2300 and 0300 LST, in good agreement with the GPM results.

Along the south Java transects, heavier precipitation aligns either with the land breeze, or the point of transition from sea breeze to land breeze. The TRMM precipitation contours show a smooth transition from slower to faster propagation speeds, as in the Sumatra case. This may reflect a peculiarity with the TRMM dataset, or the fact that the GPM and TRMM datasets cover different time periods. As in the case of Sumatra, the heavier precipitation in the transition region between sea and land breeze is consistent with the convergence mechanism described by Kilpatrick et al. (2017).

In the Java Sea, the arched precipitation contours are consistent with the propagation of precipitation from each coastline, which then meets in the Java Sea. The heavier precipitation is aligned with the land breezes from both Java and Borneo, and the heaviest precipitation occurs when these breezes converge. This could reflect either a combination of convective systems that have propagated out from each coast, or the generation of additional systems through surface convergence.

The New Guinea transects (Fig. 8) show the clearest evidence of offshore propagation among the transects considered in this study. In both GPM and TRMM, propagation of both enhanced and suppressed precipitation is clear up to $300 \mathrm{~km}$ from the coast. Moreover, the enhanced and suppressed precipitation coincide with the land and sea breezes, respectively. This is consistent with the hypothesis of Mapes et al. (2003) and the modeling results of Vincent and Lane (2016a) and Hassim et al. (2016), that it is the lower to middle troposphere cooling anomaly associated with the land breeze that triggers precipitation as it propagates out from the coast. 

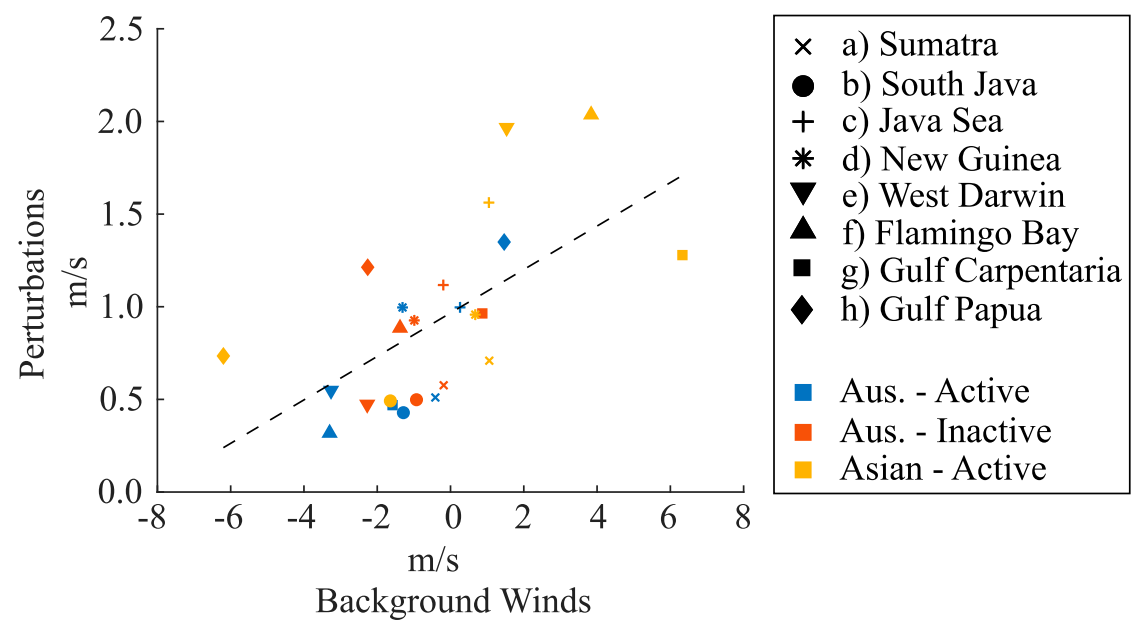

FIG. 16. Relationship between background wind speed and perturbation amplitude for transects shown in Fig. 2. Positive and negative background winds are offshore and onshore, respectively. Dashed line gives linear least squares fit—Pearson's correlation coefficient is 0.62 .

Rauniyar and Walsh (2011, p. 344) found that along the north coast of New Guinea, precipitation peaked just offshore between 0500 and 0700 LST, then propagated at least $200 \mathrm{~km}$ offshore. Their timing results agree well with those of GPM, but less well with TRMM, which peaks close to the coast at around 0800 LST. These differences may be the result of the different time periods studied, or of averaging across a broader set of transects to produce Fig. 8 than those considered by Rauniyar and Walsh (2011).

Recall that CSCAT and RSCAT are composited over continuous 15- and 22-month time periods, respectively; therefore, the results of section 3 cannot capture the effects of season/intraseasonal variability on the diurnal cycle of surface winds. Recall that Rauniyar and Walsh (2011) and Peatman et al. (2014) observed that over the islands of the Maritime Continent, particular those with high topography, diurnal cycles of precipitation were strengthened during MJO suppressed conditions. They argued that this was partly explained by the reduced cloud cover during the MJO suppressed phase enhancing the surface heating cycle, and therefore strengthening land-sea and mountain-valley breezes, with stronger sea/valley breezes triggering more convection as the breezes flow up the topography of the major islands. Moreover, Love et al. (2011) argued that causation also goes in the other direction, with increased daytime convection over land deepening the tropical heating cycle and therefore producing stronger sea breezes.

The results of section 4 suggest that changes in the overall mean winds during different seasonal/intraseasonal time periods impact the diurnal cycle of surface winds considerably. For example, in the Gulf of Papua during the MJO active regime, there are strong onshore winds during the Asian monsoon season, and

TABLE 3. Summary of the perturbation and background wind speeds over each set of transects. Positive speeds indicate a wind blowing away from coastlines (land-breeze direction), negative speeds indicate a wind blowing toward coastlines (sea-breeze direction). Also shown are the propagation speeds of the land-sea breeze signal rounded to the nearest $5 \mathrm{~m} \mathrm{~s}^{-1}$, with $c_{1}$ the slower speeds close to the coastlines, and $c_{2}$ the faster speeds farther offshore. Note that $c_{1}$ is generally only detectable for the land breeze.

\begin{tabular}{|c|c|c|c|c|c|}
\hline Region & Dataset & Land breeze $\left(\mathrm{m} \mathrm{s}^{-1}\right)$ & Sea breeze $\left(\mathrm{m} \mathrm{s}^{-1}\right)$ & $c_{1}\left(\mathrm{~m} \mathrm{~s}^{-1}\right)$ & $c_{2}\left(\mathrm{~m} \mathrm{~s}^{-1}\right)$ \\
\hline \multirow[t]{2}{*}{ Sumatra } & RSCAT & 1.4 & -1.2 & 10 & 30 \\
\hline & CSCAT & 1.2 & -1.1 & 10 & 30 \\
\hline \multirow{2}{*}{ South Java } & RSCAT & 0.7 & -0.9 & 10 & 30 \\
\hline & CSCAT & 0.5 & -0.6 & 10 & 30 \\
\hline \multirow[t]{2}{*}{ North Java } & RSCAT & 1.5 & -1.3 & - & 30 \\
\hline & CSCAT & 1.4 & -1.7 & - & 25 \\
\hline \multirow[t]{2}{*}{ South Borneo } & RSCAT & 1.2 & -1.3 & 5 & 25 \\
\hline & CSCAT & 1.0 & -0.9 & - & 25 \\
\hline \multirow[t]{2}{*}{ New Guinea } & RSCAT & 1.1 & -1.1 & 10 & 30 \\
\hline & CSCAT & 0.9 & -1.0 & 15 & 50 \\
\hline
\end{tabular}


a)

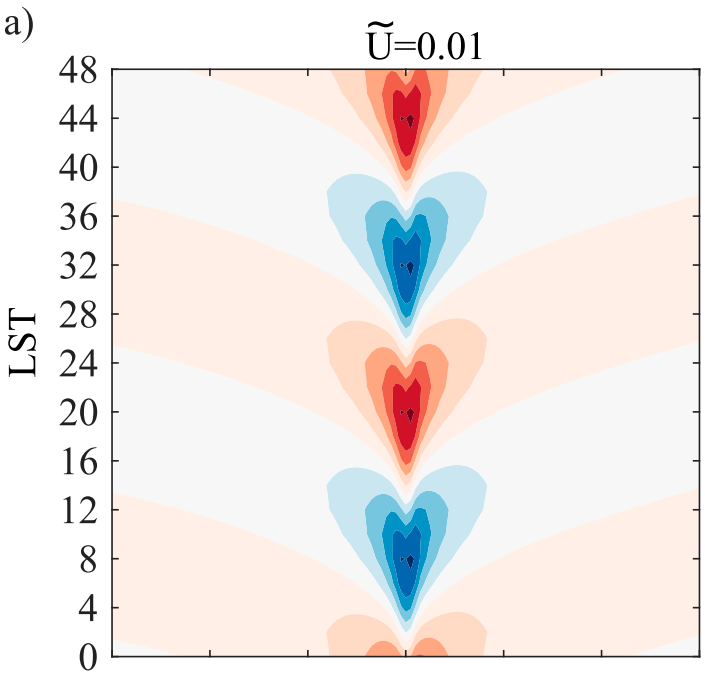

c)

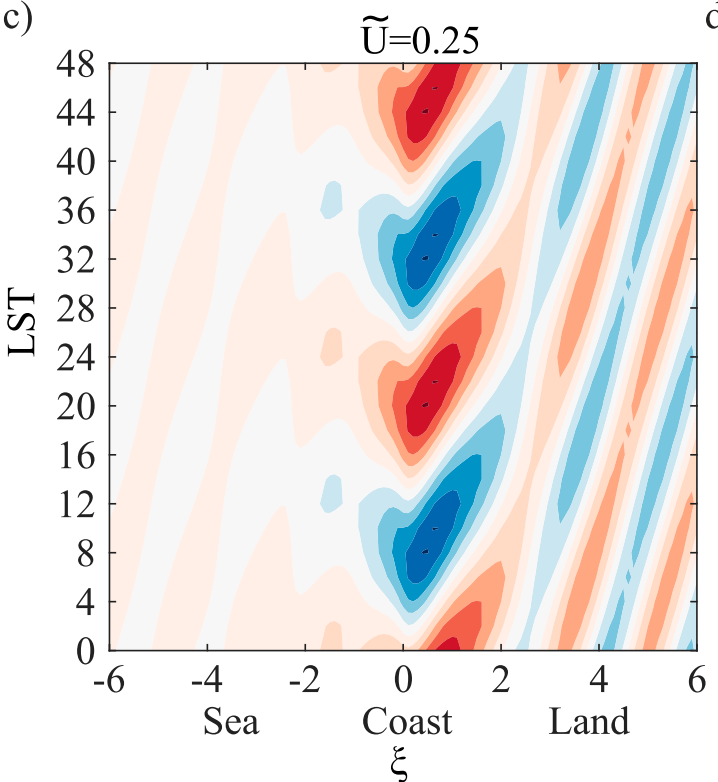

b)

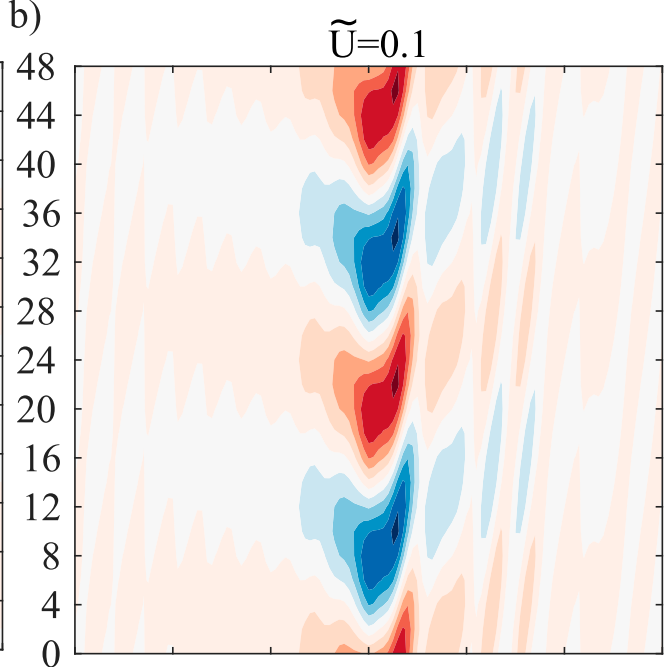

d)

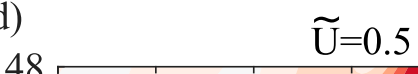

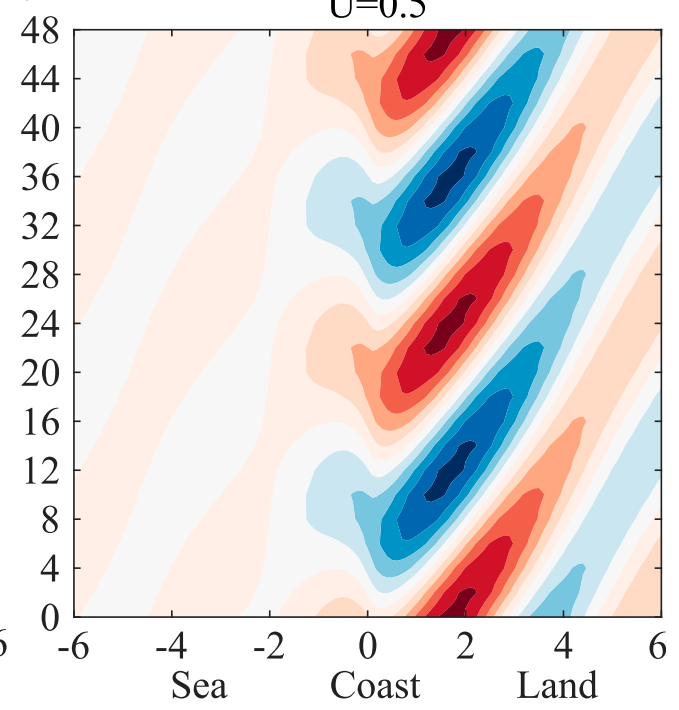

$\xi$

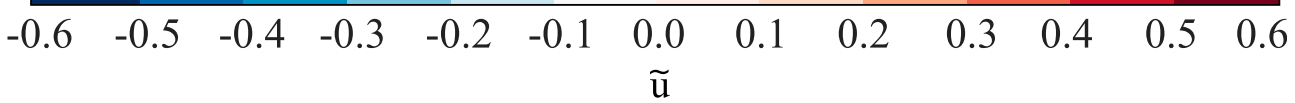

FIG. 17. Hovmöller diagrams of nondimensional horizontal surface wind perturbation, $\tilde{u}$, for various nondimensional background winds, $\tilde{U}$, calculated using the linear sea-breeze theory of Qian et al. (2009), where $\xi$ is the nondimensionalized distance from the coast.

weak offshore winds during the Australian monsoon season, with the wind perturbations stronger during the Australian monsoon season. However, less than $500 \mathrm{~km}$ away off the west coast of north Queensland, the background winds are offshore during the Asian monsoon season, but slightly onshore during the Australian monsoon. Here, the perturbations are stronger during the Asian monsoon season. This occurs despite the OLR being at least $40 \mathrm{~W} \mathrm{~m}^{-2}$ higher in the Australian monsoon season in both locations (see Fig. 13). Figure 16 indicates similar results across many regions of the Maritime Continent. The least affected regions include the south coasts of Sumatra and south Java, and the north coast of New Guinea, where background winds are mostly parallel to the coast (see Fig. 12).

This observed relationship between the mean winds and the intensity of perturbations is consistent with the linear theory of the land-sea breeeze. Building on the work of Rotunno (1983), Qian et al. (2009) studied tropical land and sea breezes by considering them as 
small perturbations $\tilde{u}$ against a background wind $\tilde{U}$. Qian et al. simplified the model of Rotunno by considering just the equatorial case, effectively removing the Coriolis force entirely.

Figure 17 provides Hovmöller diagrams that show how the surface winds perpendicular to the coast in the nondimensional solution of Qian et al. (2009) evolve with time for various values of the nondimensional background wind $\tilde{U}$. When $\tilde{U}=0.01$ the perturbations are largely symmetric, and propagate away from the coast in both directions. As the background wind increases, the perturbations on the downwind side of the coast initially become more erratic, and then increase in magnitude - note that this is true of both the onshore and offshore perturbations.

Qian et al. (2009) described this behavior in terms of three classes of waves. First are those that propagate from the coast in the opposite direction to the background wind, second are those that propagate in the same direction as the background wind but at a faster speed, and third are those that propagate in the same direction as the background wind but at a slower speed. Increasing the background wind increases the Doppler shifting of the first and second classes of waves: thus, the gravity wave phase lines become steeper on the upwind side of the coast, and shallower on the downwind side of the coast (Qian et al. 2009, their Fig. 5). This produces surface wind perturbations on the downwind side of the coast that are spread out over a larger horizontal distance. Furthermore, increasing the background wind increases the dominance of the third class of waves, which generate flow similar to the flow past a stationary heat source-this is the dominant mechanism in Fig. 17d.

\section{Conclusions}

In this study, we reviewed the diurnal variations in wind and precipitation over the Maritime Continent region. Although this topic has been addressed through modeling studies (Birch et al. 2016; Vincent and Lane 2016a; Love et al. 2011), satellite precipitation estimates (Peatman et al. 2014; Mori et al. 2004), theoretical considerations (Rotunno 1983; Qian et al. 2009; Du and Rotunno 2018), and single scatterometer-based studies (Gille et al. 2003, 2005), this is the first study that brings together multiple scatterometer and satellite precipitation estimates to create a detailed climatology of diurnal variations in the region. While the key results and propagation speeds are consistent with earlier studies, this study highlights subtle differences in the relationship between precipitation and land-sea breeze circulations along different coastlines, demonstrating a complicated blend of orographic forcing, background flow, and sea-breeze kinematics.
The RSCAT and CSCAT Hovmöller diagrams presented in section 3 provide two independent estimates of the diurnal cycle of surface winds near straight coastlines of the Maritime Continent. Despite the inconsistent time periods and methodological differences, both agree on timing to within $2 \mathrm{~h}$, and amplitude to within $0.2 \mathrm{~m} \mathrm{~s}^{-1}$. Across the four sets of transects studied, land-sea breeze processes are evident $400-600 \mathrm{~km}$ offshore, with an open ocean diurnal cycle detectable $400-800 \mathrm{~km}$ offshore in the case of Sumatra. The diurnal cycle of precipitation observed by TRMM and GPM suggests that different mechanisms likely account for the different precipitation propagation behaviors observed off each coastline. Off the southwest coast of Sumatra and the south coast of Java, the timing of the peak precipitation relative to that of the land-sea breezes suggest the mechanisms outlined in Kilpatrick et al. (2017) are likely at play. In the Java Sea region, precipitation appears to propagate from both coastlines and peak over the sea. This occurs when the land breezes from the north coast of Java and the south coast of Borneo are active, suggesting that either surface convergence is playing a role in triggering new convection, or that there is additional destabilization of the lower to midtroposphere due to the superpositioning of gravity waves originating from both south Borneo and north Java. Off the north coast of New Guinea, precipitation propagates at the same time as the land breeze perturbations, and at a similar speed. This suggests the mechanism described by Mapes et al. (2003) is active in this region, in agreement with the WRF simulations of Vincent and Lane (2016a) and Hassim et al. (2016).

Section 4 shows that seasonal/intraseasonal changes to the background wind state affect the diurnal cycle of surface winds considerably. Variations with cloud cover, such as those outlined by Rauniyar and Walsh (2011) and Peatman et al. (2014), are hard to detect, which is consistent with the modeling work of Vincent and Lane (2016a). The effect of the background wind on the diurnal cycle is qualitatively consistent with the linear theory of Qian et al. (2009). However, the symmetry of the ASCAT perturbation composites considered in section 4 results by calculating perturbations at just two times of day, and future work should therefore test this relationship using more temporally complete datasets.

In summary, this study has explored the complexity of surface wind and precipitation relationships over the Maritime Continent, a region that is a source of errors in all classes of atmospheric models. In addition to surface properties, the vertical structure of land-sea breezes is known to affect precipitation, but further work is required to observe these structures and evaluate their representation in atmospheric models. 
Acknowledgments. Funding for this study was provided for Ewan Short by the Australian Research Council's Centre of Excellence for Climate System Science (CE110001028), and for Todd Lane and Claire Vincent by the Australian Research Council's Centre of Excellence for Climate Extremes (CE170100023). HY2SCAT data were provided by the Chinese National Satellite Ocean Application Service. Thanks also to Craig Epifanio of Texas A\&M University and Yu Du of Sun Yat-Sen University for their help with the linear theory of Qian et al. (2009), and to three anonymous reviewers for their helpful suggestions. The code written for this study is freely available online (Short 2018).

\section{REFERENCES}

Bergemann, M., C. Jakob, and T. P. Lane, 2015: Global detection and analysis of coastline-associated rainfall using an objective pattern recognition technique. J. Climate, 28, 7225-7236, https://doi.org/10.1175/JCLI-D-15-0098.1.

Birch, C. E., S. Webster, S. C. Peatman, D. J. Parker, A. J. Matthews, Y. Li, and M. E. E. Hassim, 2016: Scale interactions between the MJO and the western Maritime Continent. J. Climate, 29, 2471-2492, https://doi.org/10.1175/JCLI-D-15-0557.1.

Brown, A. L., C. L. Vincent, T. P. Lane, E. Short, and H. Nguyen, 2017: Scatterometer estimates of the tropical sea-breeze circulation near Darwin, with comparison to regional models. Quart. J. Roy. Meteor. Soc., 143, 2818-2831, https://doi.org/ 10.1002/qj.3131.

Bureau of Meteorology, 2018: Madden-Julian Oscillation (MJO). Accessed 2 November 2018, http://www.bom.gov.au/climate/ $\mathrm{mjo} /$.

Dai, A., and C. Deser, 1999: Diurnal and semidiurnal variations in global surface wind and divergence fields. J. Geophys. Res., 104, 31 109-31 125, https://doi.org/10.1029/1999JD900927.

Du, Y., and R. Rotunno, 2018: Diurnal cycle of rainfall and winds near the south coast of China. J. Atmos. Sci., 75, 2065-2082, https://doi.org/10.1175/JAS-D-17-0397.1.

Earth Observation Portal, 2018a: HY-2A (Haiyang-2A)/Ocean-2A. Accessed 2 November 2018, https://directory.eoportal.org/web/ eoportal/satellite-missions/h/hy-2a.

_- 2018b: MetOp (Meteorological Operational Satellite Program of Europe). Accessed 2 November 2018, https:// directory.eoportal.org/web/eoportal/satellite-missions/m/ metop.

Gille, S. T., S. G. Llewellyn Smith, and S. M. Lee, 2003: Measuring the sea breeze from QuikSCAT scatterometry. Geophys. Res. Lett., 30, 1114, https://doi.org/10.1029/2002GL016230.

,-- , and N. Statom, 2005: Global observations of the land breeze. Geophys. Res. Lett., 32, L05605, https://doi.org/10.1029/ 2004GL022139.

Hassim, M. E. E., T. P. Lane, and W. W. Grabowski, 2016: The diurnal cycle of rainfall over New Guinea in convectionpermitting WRF simulations. Atmos. Chem. Phys., 16, 161175, https://doi.org/10.5194/acp-16-161-2016.

Hollander, M., D. A. Wolfe, and E. Chicken, 2014: Nonparametric Statistical Methods. 3rd ed. Wiley, 848 pp.

Hou, A. Y., and Coauthors, 2014: The global precipitation measurement mission. Bull. Amer. Meteor. Soc., 95, 701-722, https://doi.org/10.1175/BAMS-D-13-00164.1.
Igel, A. L., S. C. van den Heever, and J. S. Johnson, 2018: Meteorological and land surface properties impacting sea breeze extent and aerosol distribution in a dry environment. J. Geophys. Res. Atmos., 123, 22-37, https://doi.org/10.1002/2017JD027339.

Indian Space Research Organisation, 2007: Oceansat-2. Publications and Public Relations ISRO Headquarters, accessed 2 November 2018, https://directory.eoportal.org/web/eoportal/ satellite-missions/o/oceansat-2.

Kilpatrick, T., S.-P. Xie, and T. Nasuno, 2017: Diurnal convectionwind coupling in the Bay of Bengal. J. Geophys. Res. Atmos., 122, 9705-9720, https://doi.org/10.1002/2017JD027271.

Laing, A., and J. L. Evans, 2018: Introduction to tropical meteorology. Accessed 2 November 2018, http://www.meted.ucar.edu/ tropical/textbook_2nd_edition/.

Liu, C., and M. W. Moncrieff, 1996: A numerical study of the effects of ambient flow and shear on density currents. Mon. Wea. Rev., 124, 2282-2303, https://doi.org/10.1175/1520-0493(1996) 124<2282:ANSOTE $>2.0 . \mathrm{CO} ; 2$.

Love, B. S., A. J. Matthews, and G. M. S. Lister, 2011: The diurnal cycle of precipitation over the Maritime Continent in a highresolution atmospheric model. Quart. J. Roy. Meteor. Soc., 137, 934-947, https://doi.org/10.1002/qj.809.

Madden, R. A., and P. R. Julian, 1971: Detection of a 40-50 day oscillation in the zonal wind in the tropical Pacific. J. Atmos. Sci., 28, 702-708, https://doi.org/10.1175/1520-0469(1971) 028<0702:DOADOI $>2.0$. CO;2.

— , and - 1972: Description of global-scale circulation cells in the tropics with a 40-50 day period. J. Atmos. Sci., 29, 1109-1123, https://doi.org/10.1175/1520-0469(1972)029<1109: DOGSCC $>2.0 . \mathrm{CO} ; 2$.

Mapes, B. E., T. T. Warner, and M. Xu, 2003: Diurnal patterns of rainfall in northwestern South America. Part III: Diurnal gravity waves and nocturnal convection offshore. Mon. Wea. Rev., 131, 830-844, https://doi.org/10.1175/1520-0493(2003) $131<0830$ :DPORIN $>2.0$. CO; 2 .

Moncrieff, M. W., and T. P. Lane, 2015: Long-lived mesoscale systems in a low-convective inhibition environment. Part II: Downshear propagation. J. Atmos. Sci., 72, 4319-4336, https:// doi.org/10.1175/JAS-D-15-0074.1.

Mori, S., and Coauthors, 2004: Diurnal land-sea rainfall peak migration over Sumatera Island, Indonesian Maritime Continent, observed by TRMM satellite and intensive rawinsonde soundings. Mon. Wea. Rev., 132, 2021-2039, https://doi.org/ 10.1175/1520-0493(2004)132<2021:DLRPMO > 2.0.CO;2.

Moroni, D., B. Stiles, and A. Fore, 2013: Oceansat-2 level 2B user guide. Tech. Rep. CL 13-1002, California Institute of Technology, Pasadena, CA, accessed 2 November 2018, 16 pp., $\mathrm{ftp} / / /$ podaac.jpl.nasa.gov/OceanWinds/oceansat2/L2B/oscat/ jpl/docs/os2_oscat_12b_ug_v1_0.pdf.

,,- D. Tyler, and A. Fore, 2016: Rapidscat level 2B netCDF guide document. Tech. Rep. CL 16-1418, California Institute of Technology, Pasadena, CA, accessed 2 November 2018, 31 pp., ftp://podaac.jpl.nasa.gov/allData/rapidscat/L2B12/docs/ rscat_12b_user_guide_v1.pdf.

NASA, 2018a: Global precipitation measurement. NASA, accessed 2 November 2018, http://pmm.nasa.gov/gpm.

—_, 2018b: Physical Oceanography Distributed Active Archive Center. NASA, accessed 2 November 2018, https:// podaac.jpl.nasa.gov/.

_, 2018c: STORM. NASA, accessed 2 November 2018, https:// storm.pps.eosdis.nasa.gov/storm.

, 2018d: Tropical Rainfall Measuring Mission. NASA, accessed 2 November 2018, https://trmm.gsfc.nasa.gov/. 
NOAA, 2018: Cold \& warm episodes by season. NASA, accessed 2 November 2018, http://origin.cpc.ncep.noaa.gov/ products/analysis_monitoring/ensostuff/ONI_v5.php.

__ 2019: NOAA daily (non-interpolated) outgoing longwave radiation (OLR). NASA, accessed 2 November 2018, https://www.esrl.noaa.gov/psd/data/gridded/data.uninterp_ OLR.html\#detail.

National Satellite Ocean Application Service, 2013: HY-2A satellite user's guide. Tech. Rep., National Satellite Ocean Application Service, Beijing, China, 7 pp., https://www.eumetsat.int/website/ $\mathrm{wcm} / \mathrm{idc} / \mathrm{idcplg}$ ? IdcService $=$ GET_FILE\&dDocName $=$ PDF_HY-2A_USER_GUIDE\&RevisionSelectionMethod $=$ LatestReleased\&Rendition $=$ Web.

_ 2018: National Satellite Ocean Application Service. Accessed 2 November 2018, http://nsoas.org.cn/.

Neale, R., and J. Slingo, 2003: The Maritime Continent and its role in the global climate: A GCM study. J. Climate, 16, 834-848, https://doi.org/10.1175/1520-0442(2003)016<0834:TMCAIR > 2.0.CO;2.

Negri, A. J., T. L. Bell, and L. Xu, 2002: Sampling of the diurnal cycle of precipitation using TRMM. J. Atmos. Oceanic Technol., 19, 1333-1344, https://doi.org/10.1175/1520-0426(2002) 019<1333:SOTDCO $>2.0 . C O ; 2$.

Nel, D., and C. V. D. Merwe, 1986: A solution to the multivariate Behrens-Fisher problem. Commun. Stat. Theory Methods, 15, 3719-3735, https://doi.org/10.1080/03610928608829342.

Peatman, S. C., A. J. Matthews, and D. P. Stevens, 2014: Propagation of the Madden-Julian Oscillation through the Maritime Continent and scale interaction with the diurnal cycle of precipitation. Quart. J. Roy. Meteor. Soc., 140, 814-825, https:// doi.org/10.1002/qj.2161.

Qian, T., C. C. Epifanio, and F. Zhang, 2009: Linear theory calculations for the sea breeze in a background wind: The equatorial case. J. Atmos. Sci., 66, 1749-1763, https://doi.org/ 10.1175/2008JAS2851.1.

,-- , and,- 2012 : Topographic effects on the tropical land and sea breeze. J. Atmos. Sci., 69, 130-149, https://doi.org/ 10.1175/JAS-D-11-011.1.

Ramage, C. S., 1968: Role of a tropical "Maritime Continent" in the atmospheric circulation. Mon. Wea. Rev., 96, 365-370, https:// doi.org/10.1175/1520-0493(1968)096<0365:ROATMC >2.0.CO;2.

Rauniyar, S. P., and K. J. E. Walsh, 2011: Scale interaction of the diurnal cycle of rainfall over the Maritime Continent and Australia: Influence of the MJO. J. Climate, 24, 325-348, https://doi.org/10.1175/2010JCLI3673.1.

Rencher, A. C., 1998: Multivariate Statistical Inference and Applications. Wiley, 592 pp.

Robinson, F. J., M. D. Patterson, and S. C. Sherwood, 2013: A numerical modeling study of the propagation of idealized sea-breeze density currents. J. Atmos. Sci., 70, 653-668, https:// doi.org/10.1175/JAS-D-12-0113.1.

Rotunno, R., 1983: On the linear theory of the land and sea breeze. J. Atmos. Sci., 40,1999-2009, https://doi.org/10.1175/ 1520-0469(1983)040<1999:OTLTOT>2.0.CO;2.

Royal Netherlands Meteorological Institute, 2013: ASCAT wind product user manual (v1.13). Royal Netherlands Meteorological Institute, 23 pp., http://projects.knmi.nl/scatterometer/ old_manuals/ss3_pm_ascat_1.13.pdf.

Short, E., 2018: eshort0401/scatterometer_composites. Accessed 2 November 2018, https://github.com/eshort0401/scatterometer composites.

Skamarock, W., and Coauthors, 2008: A description of the Advanced Research WRF version 3. NCAR Tech. Note NCAR/ TN-475+STR, 113 pp., https://doi.org/10.5065/D68S4MVH.

Tulich, S. N., and B. E. Mapes, 2008: Multiscale convective wave disturbances in the tropics: Insights from a two-dimensional cloud-resolving model. J. Atmos. Sci., 65, 140-155, https:// doi.org/10.1175/2007JAS2353.1.

Verhoef, A., M. Portabella, and A. Stoffelen, 2012: High-resolution ASCAT scatterometer winds near the coast. IEEE Trans. Geosci. Remote Sens., 50, 2481-2487, https://doi.org/10.1109/ TGRS.2011.2175001.

Vincent, C. L., and T. P. Lane, 2016a: Evolution of the diurnal precipitation cycle with the passage of a Madden-Julian oscillation event through the Maritime Continent. Mon. Wea. Rev., 144, 1983-2005, https://doi.org/10.1175/MWR-D15-0326.1.

$\longrightarrow$, and 2016b: Maritime Continent austral summer climatology v1.0. NCI National Research Data Collection, digital media, accessed 2 November 2018, http://geonetwork.nci.org.au/ geonetwork/srv/eng/catalog.search\#/metadata/f5210_8718_ 6512_7201.

— observed and modeled intraseasonal, mesoscale, and diurnal variations over the Maritime Continent. J. Climate, 30, 38073828, https://doi.org/10.1175/JCLI-D-16-0688.1.

Wheeler, M. C., and H. H. Hendon, 2004: An all-season realtime multivariate MJO index: Development of an index for monitoring and prediction. Mon. Wea. Rev., 132, 1917-1932, https://doi.org/10.1175/1520-0493(2004)132<1917:AARMMI> 2.0.CO;2.

Wilks, D. S., 2011: Statistical Methods in the Atmospheric Sciences. 3rd ed. International Geophysics Series, Vol. 100, Academic Press, 704 pp.

Wu, Q., and G. Chen, 2015: Validation and intercomparison of HY-2A/MetOp-A/Oceansat-2 scatterometer wind products. Chin. J. Oceanol. Limnol., 33, 1181-1190, https://doi.org/10.1007/ s00343-015-4160-4. 